\title{
Enhanced antibacterial properties of orthopedic implants by titanium nanotube surface modification: a review of current techniques
}

This article was published in the following Dove Press journal: International Journal of Nanomedicine

\author{
Yuehong Li ${ }^{\prime}$ \\ Yue Yang ${ }^{2}$ \\ Ruiyan $\mathrm{Li}^{\prime}$ \\ Xiongfeng Tang \\ Deming Guol \\ Yun'an Qing' \\ Yanguo Qin' \\ 'Orthopaedic Medical Center, The \\ Second Hospital of Jilin University, \\ Changchun, People's Republic of China; \\ ${ }^{2}$ Department of Cardiology, China-Japan \\ Union Hospital of Jilin University, \\ Changchun, People's Republic of China
}

Correspondence: Yun'an Qing; Yanguo Qin

Orthopaedic Medical Center, The Second Hospital of Jilin University, Changchun

People's Republic of China

Email qingyunan@hotmail.com;

qinyg@jlu.edu.cn

\begin{abstract}
Prosthesis-associated infections are one of the main causes of implant failure; thus it is important to enhance the long-term antibacterial ability of orthopedic implants. Titanium dioxide nanotubes (TNTs) are biomaterials with good physicochemical properties and biocompatibility. Owing to their inherent antibacterial and drug-loading ability, the antibacterial application of TNTs has received increasing attention. In this review, the process of TNT anodizing fabrication is summarized. Also, the mechanism and the influencing factors of the antibacterial property of bare TNTs are explored. Furthermore, different antibacterial strategies for carrying drugs, as well as modifications to prolong the antibacterial effect and reduce drug-related toxicity are discussed. In addition, antibacterial systems based on TNTs that can automatically respond to infection are introduced. Finally, the currently faced problems are reviewed and potential solutions are proposed. This review provides new insight on TNT fabrication and summarizes the most advanced antibacterial strategies involving TNTs for the enhancement of long-term antibacterial ability and reduction of toxicity.
\end{abstract}

Keywords: antibacterial property, drug delivery, titanium dioxide nanotube, orthopedic implant, surface modification

\section{Introduction}

Prosthesis implantation is an effective approach for the treatment of orthopedic diseases, such as bone defects. As the human lifespan increases and quality of life improves, the demand for prosthesis is also increasing. ${ }^{1,2}$ Titanium and its alloys are the most commonly used implant materials owing to their favorable physical profiles and biocompatibility. Unfortunately, they are biologically inert and cannot resist infection. $^{3,4}$ Prosthetic-associated infection is one of the main causes of implant failure. Numerous factors, such as improper surgery, long operation time during surgery, and post-surgery contamination from adjacent tissues and hematogenous sources, may lead to infection. ${ }^{5}$ During infection, bacteria secrete a protective biofilm, which can accumulate various bacteria from blood or other sources, and protect bacteria from both the immune system and antibacterial agents. In this case, the required bactericidal ability is 1000-fold higher than normal, greatly increasing antibacterial difficulty. ${ }^{6-8}$ Currently, the clinical treatments for postoperative prosthesis infection are surgery and administration of antibiotics. 9 Surgeries such as one- or two-stage exchange are expensive and cast secondary 
damage to the patient. ${ }^{9}$ Also, most of the drugs delivered through conventional methods are decomposed by the metabolism, and the remaining drug is distributed systemically. This results in low drug concentration at the infection sites, which cannot effectively kill bacteria with biofilm. However, increasing the drug concentration by augmenting the total intake quantity leads to drug overdose and cytotoxicity. ${ }^{10}$ Therefore, the development of an antibacterial implant with properties that impair bacteria adhesion, deliver antibacterial agents, and reduce the risk of drug overdose is essential to fight postoperative orthopedic infection.

Based on titanium, the most commonly used prosthetic material for orthopedics, there are two major surface treatments for preventing postoperative prosthesis infection, namely surface modifications and coatings. ${ }^{11}$ Titanium dioxide nanotubes (TNTs) are nanostructures produced by surface modification. They are highly ordered nanotubes fabricated on titanium sheets with physical and chemical properties. They are easy to fabricate and the designated dimension may be obtained by varying reaction parameters. In addition, TNTs exhibit good biocompatibility and studies have shown that they can enhance the adhesion and proliferation of osteoblasts but to kill bacteria. Furthermore, although toxicity derived from the debris generated by corrosion is a common problem of titanium-based materials, the use of thick titanium dioxide $\left(\mathrm{TiO}_{2}\right)$ layers renders TNTs less toxic. ${ }^{12}$ In vivo, experiments have not found inflammation and fibrous vesicles around TNTs, proving that they do not cause a strong immune response. ${ }^{3,13}$ TNTs may also serve as drug-loading platforms for multiple biofunctions, such as osteogenesis and antibacterial ability. Notably, the toxicity caused by the loading of the reagent is determined by the reagent itself and its local concentration. Therefore, controlling the release of reagents is necessary. ${ }^{12,14,15}$ These advantages render TNTs a great candidate for use in commercialized orthopedic implants with good antibacterial properties.

The antibacterial properties of nanostructures have been reported in recent years. ${ }^{16-18}$ However, there is no specific review summarizing the antibacterial properties of TNT nanostructures. Several reviews have discussed TNTs as drug-loading platforms for various applications. ${ }^{10,19}$ Regrettably, several methods mentioned in these reviews are not suitable for the treatment of infection, and the antibacterial application of TNTs is not limited to the loading of drugs. Although TNTs can kill bacteria via the production of reactive oxygen species through photocatalysis, ${ }^{20,21}$ this light-dependent antibacterial ability is limited in orthopedic implants.

Therefore, in this review, the mechanism, development, and shortcomings of TNT anodizing fabrication are discussed. The antibacterial ability of TNT nanotopography is explored, and a hypothesis regarding the relationship between the diameter of the TNTs and antibacterial ability is proposed. Also, for the antibacterial properties of TNTs loaded with antibacterial agents, different agents (antibiotics, antimicrobial peptides), as well as strategies for controlling drug release and reducing toxicity (tubular structure variation, coating, and doping methods) are discussed. Furthermore, modifications that automatically offer antibacterial properties during infection while preserving more antibacterial agents in non-infection periods are introduced. This review underlines the fabrication shortcomings that limit the antibacterial research of TNT nanotopology. The antibacterial mechanisms (Figure 1) and the latest advances are summarized to provide novel insights into the development of TNTs in the orthopedic antibacterial domain.

\section{Fabrication process and development of TNTs by anodization}

Current methods for the production of TNTs are sol-gel synthesis, template-assisted synthesis, hydrothermal synthesis, and electrical anodization. ${ }^{22}$ As the most currently used method, electrical anodization is a simple and economical approach to the fabrication of TNTs on Ti sheets. Besides, the desired dimensions can be achieved by manipulating electrolyte components, the $\mathrm{pH}$ value, voltage, temperature, and reaction time. ${ }^{15,23}$ In this section, the development and fabrication process of TNTs by anodization are discussed.

\section{Anodization process of TNTs}

Anodization usually takes place in an electrochemical cell (Figure 2). The system is powered by a direct current power supply. The anode is the titanium sheet to be anodized, and the inert metal (eg, platinum) is usually the cathode. Both of the electrodes are immersed in the electrolyte, which usually contains fluoride ions. The essence of TNT fabrication is the competition and equilibrium between electrochemical oxidization and chemical dissolution. ${ }^{24}$ According to the current-time curve, the reaction process can be divided into three stages, namely 


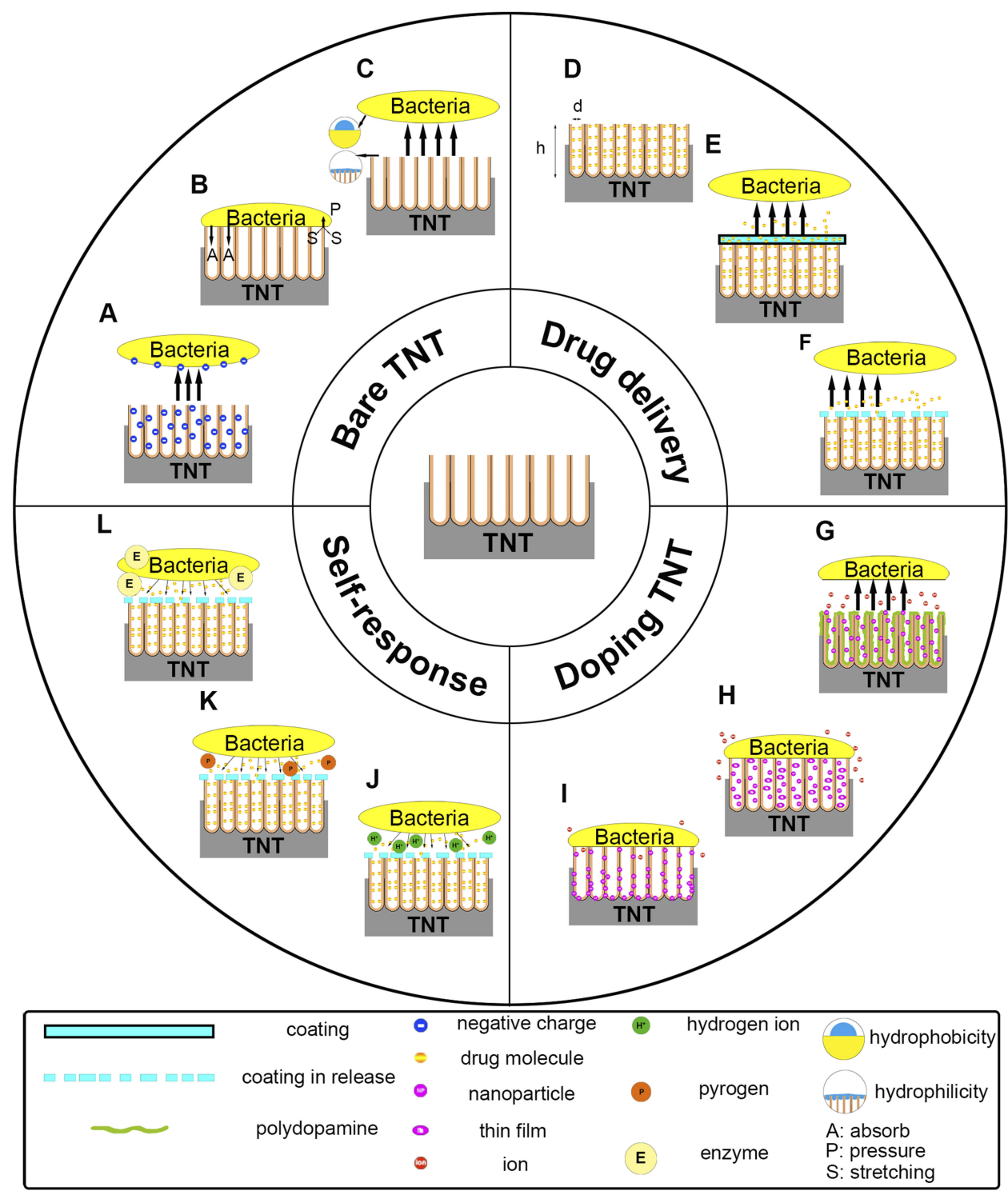

Figure I Mechanisms of antibacterial application of TNTs in orthopedic implants.

Notes: (A) Charge repulsion antibacterial property. (B) Stretching force antibacterial property. (C) Hydrophilicity prohibits bacterial adhesion. (D) Controlling drug release and loading quantity via regulation of the dimensions. (E) Controlling drug release via the application of coatings. (F) Controlling drug release and loading quantity via the use of drug-mixing coatings. (G) Distribution of NP and ion release ability of a TNT modified by polydopamine-assisted reduction. (H) Distribution of NP and ion release ability of a TNT modified by magnetron sputtering. (I) Distribution of NP and ion release ability of a TNT modified by ion implantation. (J) The pH-triggered self-response system. (K) The temperature-triggered self-response system. (L) The enzyme-triggered self-response system.

Abbreviations: NP, nanoparticles; TNT, titanium dioxide nanotube.

the initial decrease (oxidization dominance), the subsequent increase (chemical dissolution dominance), and the final steady stage (equilibrium between chemical dissolution and oxidization).

In the first stage, the titanium surface does not have a non-conductive oxide layer (barrier layer), and the oxidizing reaction is dominant over chemical dissolution. During this process, the metal surface is chemically dissolved by the electrolyte and releases $\mathrm{Ti}^{4+}$, which simultaneously reacts with $\mathrm{O}^{2-}$ produced in the electrolyte to form a thin, compact, non-conductive layer of $\mathrm{TiO}_{2}$ on the metal surface. According to reactions (1) and (2) ${ }^{23,24}$

$$
\begin{aligned}
\mathrm{Ti} & \rightarrow \mathrm{Ti}^{4+}+4 \mathrm{e}^{-} \\
\mathrm{Ti}+2 \mathrm{H}_{2} \mathrm{O} & \rightarrow \mathrm{TiO}_{2}+4 \mathrm{H}^{+}+4 \mathrm{e}^{-}
\end{aligned}
$$

At the same time, the cathode produces hydrogen, according to $(3)^{23,24}$

$$
4 \mathrm{H}_{2} \mathrm{O}+4 \mathrm{e}^{-} \rightarrow 2 \mathrm{H}_{2}+4 \mathrm{OH}^{-}
$$




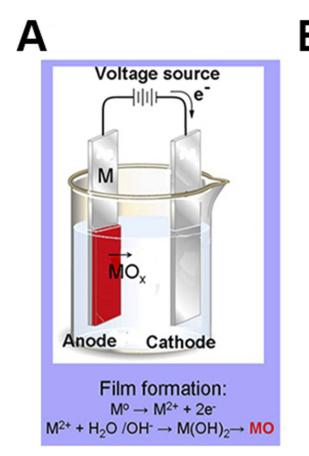

D
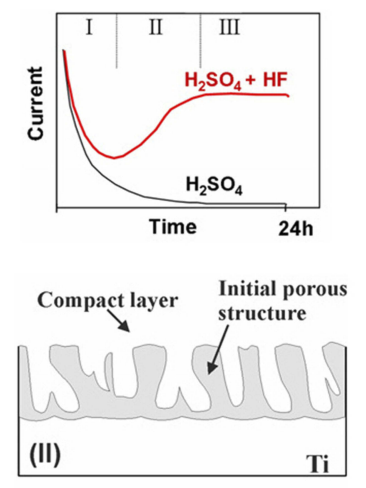
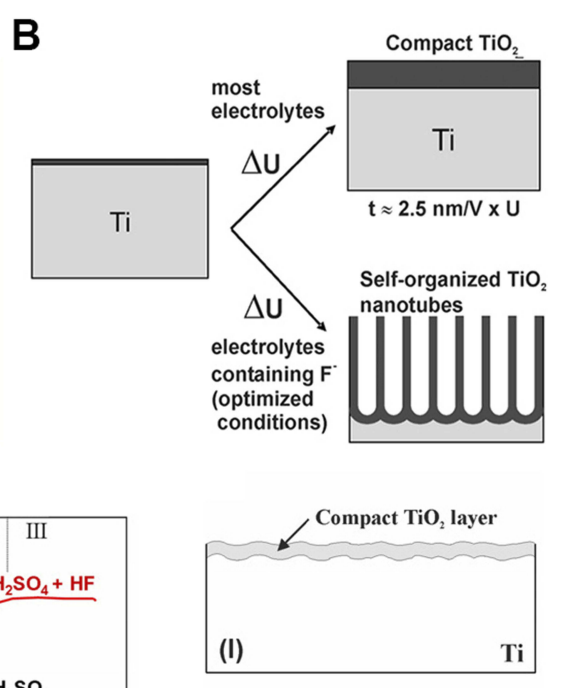

Self-organized nanotube layer

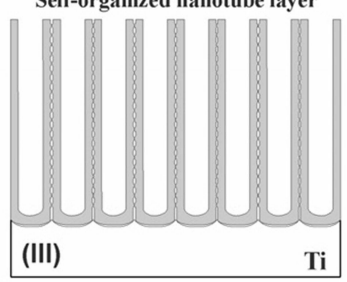

C

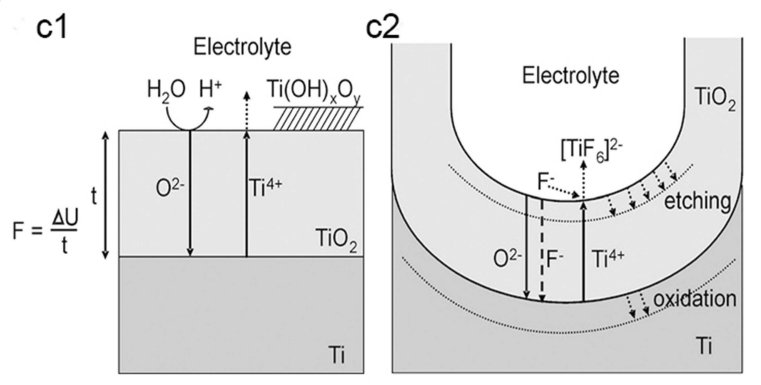

$\mathrm{E}$



Figure 2 Anodization process of TNTs. ${ }^{24}$

Note: (A) Schematic diagram of the anodizing apparatus. (B) Formation of compact or nanoporous (nanotube) titanium dioxide layers depending on anodizing parameters. (C) Schematic representation of $\mathrm{Ti}$ anodization (cl) without fluorides and (c2) with fluorides. (D) Characteristic current transients during anodization with or without fluorides in the electrolyte and variation of TNT morphology in the three reaction stages. (E) Equilibrium growth situation with equal rates of titanium dioxide dissolution (vI) and formation (v2). Reprinted from Curr Opin Solid St M, II (I-2), Macak JM, Tsuchiya H, Ghicov A, et al, TiO ${ }_{2}$ nanotubes: Self-organized electrochemical formation, properties and applications, 3-18, Copyright (2007) with permission from Elsevier.

Abbreviation: TNT, titanium dioxide nanotube.

However, the formation of a compact $\mathrm{TiO}_{2}$ layer is a selflimiting process. As the oxidization continues, the oxide layer on the metal surface gradually thickens, hampering the ability of the current to pass through. Therefore, it is difficult for $\mathrm{O}^{2-}$ to migrate to the oxide/metal interface, and growth of the oxide layer is arrested.

In the second stage, chemical dissolution is in dominance. Owing to different crystal forms and impurities, the local electric field density is uneven on the initial oxide layer, and sites with higher electric field accumulate more fluoride ions. This accumulation assists the chemical dissolution of $\mathrm{TiO}_{2}$, forming small pits on the oxide layer. According to reactions (4) and (5) ${ }^{23,24}$

$$
\begin{gathered}
\mathrm{TiO}_{2}+6 \mathrm{~F}^{-}+4 \mathrm{H}^{+} \longrightarrow\left[\mathrm{TiF}_{6}\right]^{2-}+2 \mathrm{H}_{2} \mathrm{O} \\
\mathrm{Ti}^{4+}+6 \mathrm{~F}^{-} \rightarrow\left[\mathrm{TiF}_{6}\right]^{2-}
\end{gathered}
$$

Since the bottom barrier layer of the pit becomes relatively thinner, the electric field density increases and accumulates more $\mathrm{F}^{-}$. This accumulation further accelerates the dissolution rate of $\mathrm{TiO}_{2}$, and the small pits gradually grow into small pores. The formation of gaps between walls also proceeds in this stage and determines the tubular versus the porous structure of TNTs. Regions between the small pores are unoxidized conductive Ti covered by a thick non-conductive oxide layer. As the pores grow, these regions protrude and, due to the conductive $\mathrm{Ti}$ underneath, the electric field density is extremely increased. This effect accelerates chemical dissolution even in the presence of a thick barrier layer. Since the barrier layers close to pores are thicker compared with those in the relatively distant regions, the dissolution rate is higher at the distant sites. The pores and the gaps grow simultaneously along the ion migration direction perpendicular to the substrate, eventually forming TNT structures.

In the final stage, with the consumption of $\mathrm{F}^{-}$and the production of $\left[\mathrm{TiF}_{6}\right]^{2-}$, the concentration of $\mathrm{F}^{-}$in the electrolyte is dynamically balanced. This leads to a similar rate of $\mathrm{TiO}_{2}$ dissolution on the top and bottom of the pores. As the anodization proceeds in this stage, the TNT length and the barrier layer no longer increase; however, they continue to stretch vertically toward the substrate. 


\section{Development of TNT anodization}

The development of TNT anodization is summarized into four generations based on the development of electrolytes. Electrolyte parameters like $\mathrm{F}^{-}$concentration, $\mathrm{pH}$ value, and solvent attribute (aqueous or organic, determine the dimensions of the TNTs. ${ }^{25}$ In 2001, Gong et al ${ }^{26}$ successfully fabricated well-aligned TNTs by anodization for the first time. The electrolyte they used was an aqueous solution containing $0.5-3.0 \mathrm{wt} \%$ hydrofluoric acid (HF). The use of an aqueous solution containing $\mathrm{HF}$ as the electrolyte is considered to be the first generation. Owing to the high chemical dissolution rate of TNTs in HF, the TNT length in the first generation can only reach to $500 \mathrm{~nm} .{ }^{27}$ In order to create longer TNTs, the second generation chose to adjust the electrolyte $\mathrm{pH}$ to neutral, which benefits TNT growth. ${ }^{28,29} \mathrm{HF}$ is also replaced by different fluoride-containing salts, such as sodium fluoride. These improvements significantly lower the chemical dissolution rate and the length of TNTs can reach to several microns. ${ }^{30}$ The third generation uses a fluorine-containing anhydrous polar organic solvent as electrolyte, and the TNT length can reach to $1000 \mu \mathrm{m}$. Moreover, Macak et $\mathrm{al}^{31}$ claimed that the thickness variation phenomenon observed in TNT side walls during the anterior generation methods could be eliminated by using fluoride-containing glycerol as electrolyte. The fourth generation refers to non-fluorinate electrolyte anodization. ${ }^{32,33} \mathrm{~F}^{-}$remains on the TNTs due to the fluoride-containing electrolyte, and the impact of $\mathrm{F}^{-}$during infection is ambiguous. ${ }^{6,34,35}$ This unstable factor (residual $\mathrm{F}^{-}$) can be eliminated via the fourth generation anodization.

In the future, with the development of anodization, TNTs will possess larger dimensions, nanostructures that are more controllable, chemical composition that is more precise, and broader application prospects.

\section{Potential antibacterial applications for orthopedic implants Antibacterial ability of bare TNTs}

Immunity is poor around the implant due to insufficient blood supply. Once immunity is reduced, the prosthesis is prone to infection. ${ }^{36,37}$ The nanostructures provide TNTs with long-term contact antibacterial ability. Studies have shown that the amount of adhered bacteria on TNTs was lower than that measured in the titanium control group in vitro and in vivo. ${ }^{38,39}$ Therefore, TNTs possess potential for long-term antibacterial application.
The antibacterial mechanisms are complex, including charge repulsion, membrane stretching, and surface roughness variation. Charge repulsion between TNTs and bacteria prevents the initial adhesion. Numerous bacteria possess negative charges on their surface. For example, the main components of the cell wall of Staphylococcus aureus (S. aureus) are teichoic and lipoteichoic acid, leading to a negatively charged surface. ${ }^{40}$ The terminal hydroxyl groups on the TNT surfaces also impart negative charges. The presence of the same charge between bacteria and TNTs causes repulsive forces and reduces bacterial adhesion. ${ }^{41}$ Stretching forces produced by TNT nanostructures accelerate bacterial death. Bacteria maintain their own shapes via a difference in osmotic pressure between the inner and outer subshells. ${ }^{42}$ When the bacteria come into contact with TNTs, the protruding tube walls will increase the surface pressure of bacteria and part of the membranes will suspend over the gaps. As the bacteria are continuously adsorbed onto the TNTs, the surface area of the bacteria is enlarged, and the suspended membrane stretches further, eventually leading to bacterial rupture and death. ${ }^{43}$ Surface roughness plays a major role in the antibacterial ability of TNTs. First, it may affect surface wettability. Hydrophobic surfaces tend to adhere to other hydrophobic ones because the hydrophilic structure tends to adsorb a water film, which must be removed prior to the adhesion of hydrophobic bacteria. ${ }^{44}$ The high roughness of TNTs greatly increases the hydrophilicity of the surface and hinders the adhesion of hydrophobic bacteria. Second, the effects of roughness in the nanoscale or microscale on the antibacterial properties are completely different. Bacterial adhesion decreases with an increasing surface roughness in the nanoscale $(10-100 \mathrm{~nm}) .{ }^{45-47}$ However, when the surface roughness enters or approaches the micron level, the bacterial adhesion increases in parallel with the roughness. This may be explained by the attach point theory. The theory states that, for organisms smaller than the surface microtexture, increasing roughness results in more attachment points and micro-scale refuge shelters, which will protect adherent organisms from hydrodynamic shear forces. ${ }^{40,48}$

These antibacterial mechanisms, such as membrane stretching and surface roughness, are closely related to the dimensions of TNTs. A change in the dimension parameters will lead to a complex resultant force that determines the antibacterial ability of TNTs. The diameter is an important dimension parameter. As the diameter increases, surface roughness and hydrophilicity also increase. 
However, thus far, a consensus cannot be reached regarding the relationship between the diameter of a TNT and its antibacterial ability. Several studies have shown that an increasing diameter is associated with stronger antibacterial ability. Peng et $\mathrm{al}^{6}$ claimed that TNTs with a diameter of $80 \mathrm{~nm}$ exhibited better bactericidal ability than TNTs with a diameter of $30 \mathrm{~nm}$. Simi and Rajendran ${ }^{46}$ produced TNTs with various diameters by controlling the contents of the electrolyte. They concluded that increasing TNT diameters lead to increasing hydrophilicity, thus enhancing the antibacterial ability. However, some studies yielded contradictory results. Radtke et $\mathrm{al}^{49}$ reported that TNTs prepared at $5 \mathrm{~V}$ with smaller diameters exerted a stronger antibacterial effect than other TNTs. Lewandowska et $\mathrm{al}^{50}$ claimed that the 20-30 nm TNT prepared at $4 \mathrm{~V}$ demonstrated stronger antibacterial ability against various strains of $S$. aureus than other TNTs with larger diameters. These discrepancies are attributed to the inability to precisely control variables during the experiments. Apart from the diameter, factors such as length, wall thickness, gaps between walls and crystal forms also influence the morphology of TNTs. Considering the limitations of the TNT fabrication methods, precisely controlling other variables to determine the impact of one parameter on the antibacterial property of TNTs is not possible. Therefore, although studies investigating the association between TNT diameters and antibacterial properties have been performed, they obtained varying results.

According to this evidence, this review presents a hypothesis that, assuming other parameters remain unchanged, the antibacterial ability of TNTs initially increases and subsequently decreases with the increase in TNT diameter. In the beginning, the nanoscale roughness and hydrophilicity increase in parallel with the increasing diameter, thus continuously strengthening the antibacterial ability of TNTs. However, when the diameter reaches a certain threshold, the roughness starts to approach the micron level and more attachment points appear. At the same time, although the hydrophilicity continues to increase, the effect on enhancing the antibacterial ability of an already hydrophilic surface is limited. Therefore, further increase in the diameter will reduce the antibacterial ability. Based on this theory, it may be observed that, in the continuous process of increasing TNT diameters, there is an optimum dimension to maximize the antibacterial property. Shi et $\mathrm{al}^{51}$ used broth with or without drug to culture bacteria on TNTs with increasing diameters from 30 to $100 \mathrm{~nm}$. The bacterial concentration showed an initial decrease, followed by an increase. TNTs with a diameter of $60 \mathrm{~nm}$ demonstrated the lowest bacterial concentration (Figure 3). Further research studies and more advanced fabrication methods are required to achieve the optimal antibacterial dimension.

Although the relationship between morphology and antibacterial ability is not clear, it is undeniable that bare TNTs possess antibacterial ability, and this antibacterial agent independent antibacterial ability is important for the long-term prevention of infection.

\section{Delivery platform for antibiotics and antibacterial peptides}

The structure of TNTs has an opening mouth and a closed bottom. The open tubes provide adequate space to store antibiotics and antimicrobial peptides, rendering TNTs good drug delivery platforms to fight infection. Drugs that can be delivered by TNTs are antibiotics and antibacterial peptides. Antibiotics are the most commonly used drugs for the prevention and treatment of infections. Studies showed that TNTs with antibiotics, such as gentamicin and vancomycin, demonstrated strong bactericidal ability on various bacteria. ${ }^{38,52-55}$ The antibacterial mechanisms of antibiotics are various. Specifically, they can inhibit the synthesis of cell walls and proteins, damage DNA replication, and interfere with intermediary metabolism. ${ }^{56}$ However, the application of antibiotics may trigger allergic reactions, and produce drug-resistant bacteria, making it more difficult to prevent infection. ${ }^{57}$ Compared with antibiotics, antimicrobial peptides exhibit better immunocompatibility, less toxicity, and a lower risk of developing drug resistance. In addition, they can effectively kill intracellular bacteria and reduce the risk of chronic infection. ${ }^{57} \mathrm{Li}$ et a ${ }^{58}$ combined GL13K with TNTs and found that the composite TNTs exerted a strong antibacterial effect while exhibiting better biocompatibility than metronidazole-loaded TNTs.

The currently loading methods are physical adsorption and lyophilization, both of which can achieve a drugloading efficiency $>80 \%$. ${ }^{5,59,60}$ The process of drug release is divided into two stages. The first stage is the initial release, also termed burst release. In this stage, lasting several minutes to hours, the drug-loading platform releases a large amount of drug in a short period of time, and the released drug accounts for $>60 \%$ of the total amount. The second stage is the sustained release, in which the drug is released at a continuous slow rate until the TNTs are empty. This stage can last from hours to 
A



B

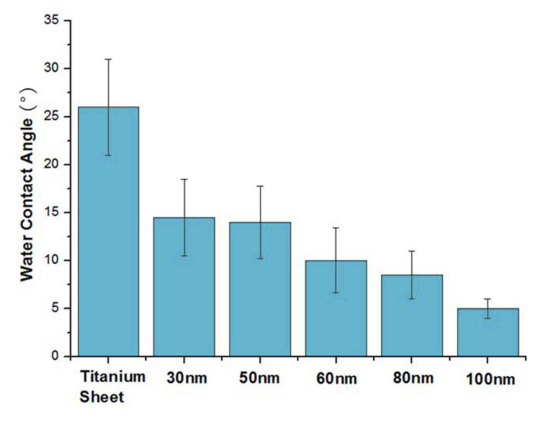

\section{C}
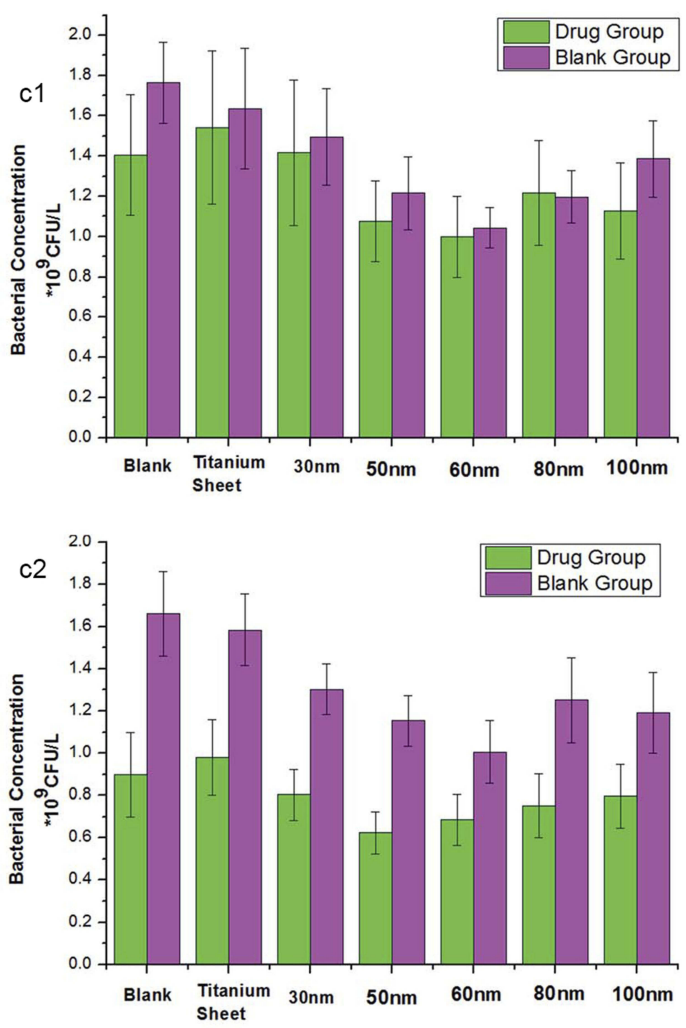

Figure 3 Impacts of diameters on the TNT antibacterial ability. ${ }^{51}$

Note: (A) FE-SEM images of TNTs with different diameters (al) $30 \mathrm{~nm}$, (a2) $50 \mathrm{~nm}$, (a3) $60 \mathrm{~nm},(\mathrm{a} 4) 80 \mathrm{~nm}$, (a5) $100 \mathrm{~nm}$, and (a6) titanium sheet. (B) Water contact angles of titanium sheets and TNTs with different diameters. (C) Bacterial concentrations of different samples after 48 hrs of culture; the bacterial solution with metronidazole concentrations of $10 \mathrm{mg} / \mathrm{L}^{-1}$ (cl) or $15 \mathrm{mg} \mathrm{mg} / \mathrm{L}^{-1}$ (c2). Reproduced from Shi XG, Xu QA, Tian A, et al, Antibacterial activities of TiO 2 nanotubes on porphyromonas gingivalis. RSC Adv. 2015;5(43):34237-34242, with permission of The Royal Society of Chemistry, http://dx.doi.org/10.1039/c5ra00804b.

Abbreviations: TNTs, titanium dioxide nanotubes; FE-SEM, field emission scanning electron microscopy.

days. The burst release is due to the initial diffusion of drug molecules under a concentration gradient from high to low, TNTs to the surrounding environment. In addition, the weak binding between drug molecules and the TNT walls also contributes to this process. ${ }^{39,61,62}$ Burst release can kill most bacteria in a short time; however, it may also lead to concentration-induced toxicity and may exhaust loaded drug to damage the long-term antibacterial ability. Although the TNTs are rinsed after the loading step to remove the unloaded drug to hinder the burst release, massive amounts of loaded drugs continue to be released from the TNTs in a short time. Therefore, increasing the drug loading, controlling the release rate, and prolonging the release time are research priorities. This section summarizes the modifications on drug-loading TNTs for prolonging the release time, controlling the release rate, and reducing cytotoxicity.

\section{TNT dimensions affect drug release}

TNT dimensions exert a significant effect on drug release. Hamlekhan et $\mathrm{al}^{63}$ fabricated a series of TNTs by combining certain voltages $(60 \mathrm{~V}, 70 \mathrm{~V}, 90 \mathrm{~V}, 120 \mathrm{~V})$ and certain durations (15 mins, 30 mins, 120 mins) as fabrication conditions. They found that increasing the diameter, length, volume, and aspect ratio could prolong drug release. Among the examined parameters, the aspect ratio was the most important. A high aspect ratio indicated a slow drug release. When the aspect ratio was $\geq 18$, the drug release could last for as long as $1 \mathrm{hr}$. Otherwise (aspect ratio <18) the drug was released in 15 mins. Bennett et $\mathrm{al}^{64}$ pointed out that TNTs with higher length carried more drug because of the larger tube volume. However, they also reported that larger diameters resulted in loss of drug during the rinsing step. This shows that there is a bottleneck in the regulation of the drug-loading capacity by simply increasing the dimension or length. Therefore, the development of TNTs with complicated structures is necessary. Shi et $\mathrm{al}^{65}$ divided the applied voltage into two consecutive stages. The first stage maintained a low voltage to prepare the small-diameter upper part, while the second stage was gradually increased to prepare the larger-diameter lower part. Finally, double-layered "pear-shaped" TNTs were obtained. These double-layered 
TNTs reduced burst release and extended release time by $50 \%$ versus TNTs with simple structures, increasing longterm release and reducing toxicity. Similar to the "pearshaped" TNTs, Zhang et al $^{66}$ reported that TNTs with a large bottom volume and a small opening mouth allowed the release of antimicrobial peptides for up to 60 days. Gulati et $\mathrm{al}^{67}$ prepared TNTs by periodically changing the anodization voltage (Figure 4), resulting in narrow-expansion-narrow periodic structures along the nanotubes. The narrowness of this structure prevented loss of the loaded drug during the rinsing steps and reduced the release rate, thus enhancing its long-term antibacterial ability.

\section{Coatings for release control}

Adjustment of the TNT dimensions can prolong drug release; however, this regulation is limited by fabrication methods. Combining TNTs with functional coatings is a good option to achieve zero-order release kinetics. ${ }^{68}$ Coatings applied to TNTs for the control of drug release are mainly polymers. ${ }^{61,62,69-71}$ These coatings can enhance certain capabilities of TNTs due to their intrinsic biological functions. ${ }^{72-75}$ There are two ways through which coatings



enhance the antibacterial properties, control drug release from TNTs, and regulate the intrinsic antibacterial ability of TNTs. For the control of drug release, coatings reduce the exposure of the loaded drug by covering the openings of the TNTs, thereby prolonging the release and enhancing the antibacterial property of the structure. Coatings such as polymethacrylic acid can form hydrogen bonds with drug molecules and further extend the release time. ${ }^{10,61}$ Enhancement of the antibacterial ability can also be achieved by the use of antibacterial coatings alone. Notably, coatings composed of several antibacterial materials may exhibit a stronger antibacterial property. ${ }^{76-78}$ Mokhtari et $\mathrm{al}^{77}$ mixed two antibacterial materials, namely chitosan (CHI) and $58 \mathrm{~S}$ bioactive glass, to obtain an advanced antibacterial coating for TNTs. This coating has shown a strong bactericidal ability against various organisms and performed better than $\mathrm{CHI}$ alone. Fabricating antibacterial coatings for antibiotic-loaded TNTs can further enhance the antibacterial ability. Feng et $\mathrm{al}^{5}$ covered gentamicin-loaded TNTs with a CHI-gentamicin coating. They found that the coating reduced drug release and increased the total amount of the delivered drug (Figure 5).

\section{C}

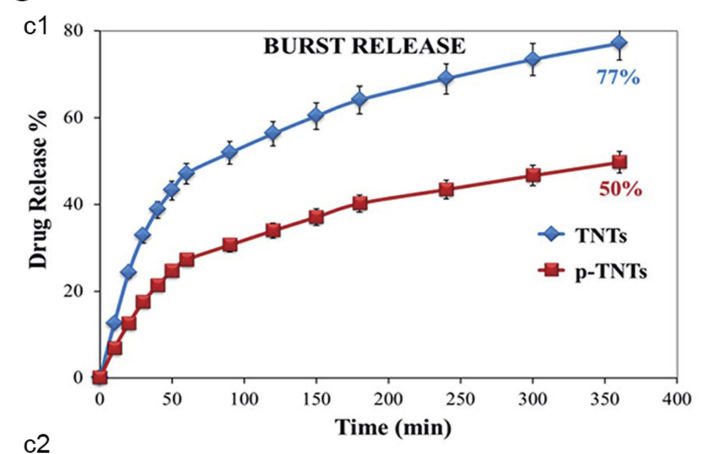

$\mathrm{c} 2$

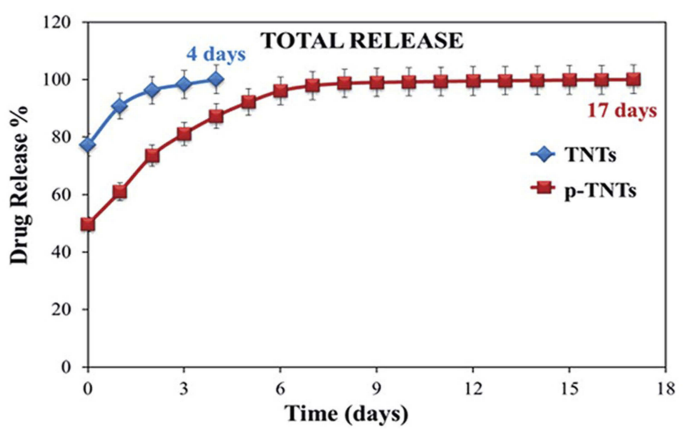

Figure 4 Impacts of TNTs with periodic structures on drug release. ${ }^{67}$

Note: (A) Schematic diagram of fabricating drug-loaded p-TNT. (B) SEM images of TNTs and p-TNTs, (bI) the top surface with opening pores, (b2) the cross section of the TNT layer, (b3) the cross section of TNTs, (b4) the cross section of p-TNTs, (b5) the high-resolution image of p-TNTs indicating a reduction of internal pore dimensions. (C) In-vitro drug-release graphs comparing the release from conventional flat TNTs and p-TNTs, (cl) initial burst release in 6 hrs, (c2) total drug release until the entire amount of the drug is exhausted. Reproduced from Gulati K, Kant K, Findlay D, Losic D. Periodically tailored titania nanotubes for enhanced drug loading and releasing performances. J Mater Chem B. 2015;3(I2):2553-2559, with permission of The Royal Society of Chemistry, http://dx.doi.org/I0.1039/c4tb0 I882f.

Abbreviations: p-TNTs, TNTs with periodic structures; TNT, titanium dioxide nanotube. 
A

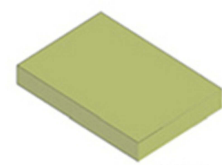

(I)Anodization Ti

(I)

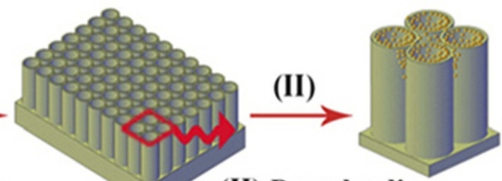

(II) Drug loading
(III)

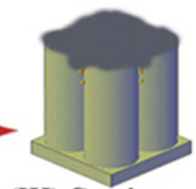

(III) Coating

Nanotube Gentamicin sulfate GSCH

B



C $\quad$ 1



c2


c3
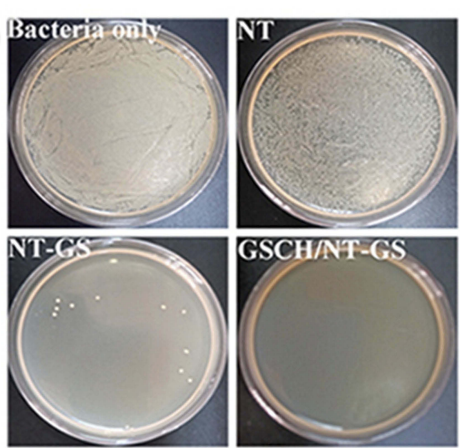

c4

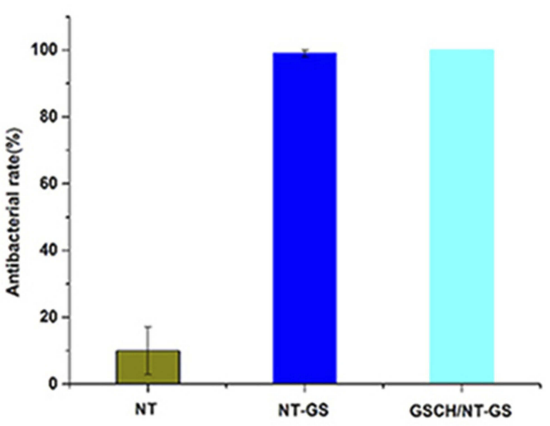

Figure 5 Drug-mixing coating controls drug loading and release. ${ }^{5}$

Note: (A) Schematic graphs of GSCH/NT-GS fabrication. (B) The kinetics of drug release. (C) Short-term bacterial incubation, (cl) SEM images of NT, TNT-GS, and GSCH/ NT-GS with bacteria colonies, (c2) bactericidal activity of TNT, TNT-GS, and GSCH/NT-GS against S. aureus, (c3) calculation of bacteria incubated for 4 hrs with or without GS, and (c4) antibacterial ratio of NT, NT-GS, and GSCH/NT-GS against S. aureus. Reprinted from Mat Sci Eng C-Mater, 62, Feng WC, Geng Z, Li ZY, et al, Controlled release behaviour and antibacterial effects of antibiotic-loaded titania nanotubes, I05-II2, Copyright (2016) with permission from Elsevier.

Abbreviations: NT, titanium nanotubes; GS, gentamicin sulfate; GSCH, coating comprising a mixture of gentamicin sulfate and chitosan; S. aureus, Staphylococcus aureus.

Drug molecules need to go through the coatings to reach the surrounding environment, and the coating thickness plays a key role in this process. ${ }^{70,71,79}$ Wang et $\mathrm{al}^{71}$ used poly(lactic-co-glycolic acid) (PLGA) to cover drug-loaded TNTs, and the duration of release lengthened with the increasing thickness of the coating layers. The one-layer 
PLGA TNTs could release the drug for 7 days, while the 10 -layer could extend the release to 40 days. Furthermore, as the number of layers increased from 0 to 10 , the burst release amount decreased from $84.2 \%$ to $27.46 \%$, greatly reducing the possibility of drug-related toxicity. However, excessive thickness may excessively retard the release of the drug. Sun et al ${ }^{70}$ prepared drug-loaded TNTs coated with PLGA (thickness: $50 \mathrm{~nm}, 250 \mathrm{~nm}$, and $800 \mathrm{~nm}$ ). The results showed that the 250-nm PLGA TNT yielded the best release kinetics. However, the release observed for the 800nm PLGA was extremely slow and the drug concentration was excessively low to be effectively bactericidal. Therefore, further research is warranted to determine the optimal coating thickness for long-term antibacterial needs.

Drug delivery via nanocarriers, such as d- $\alpha$-tocopheryl polyethylene glycol1000 succinate, can achieve simultaneous delivery of multiple drugs, increase the stability of the drug delivered in the body environment, and prolong the duration of release. ${ }^{80-82}$ Although this approach is rarely used in antibacterial therapy, it has a high antibacterial application value by carrying different antibacterial agents to achieve multi-mechanism killing. Consequently, it reduces the cytotoxicity caused by the excessive concentration of a single agent. With further research, this multi-drug delivery method may be used for antibacterial purposes in the field of implants.

\section{Doping with other antibacterial agents \\ Doping with metal nanoparticles}

Although the application of antibiotics is a major breakthrough in the field of resisting infection, it eventually leads to the development of drug resistance. The emergence of multidrug-resistant bacteria is a major problem worldwide. ${ }^{56}$ The use of substitutes of antibiotics and antibacterial peptides is one of the solutions. Metal nanoparticles (MNPs) and their oxides (eg, silver, ${ }^{83-87}$ gold, ${ }^{88-90}$ titanium dioxide, ${ }^{91}$ iron oxide, $^{92}$ and others ${ }^{93-95}$ ) are antibacterial agents and can be carried by TNTs. These nanoparticles have a high surface-tovolume ratio, and their physicochemical properties are different from those of their bulk materials. ${ }^{16}$ Studies have shown that MNPs can effectively kill drug-resistant bacteria, and it is difficult for bacteria to develop drug resistance. $^{16,96-98}$ In addition, compared with antibacterial peptides and antibiotics, MNPs can endure carrying methods under harsh conditions and permit long-term storage. Thus, they have great potential for commercial application. ${ }^{15}$
Ag nanoparticles (AgNPs) are the most widely studied antibacterial agents, with broad-spectrum antibacterial, low cytotoxicity, strong stability, and low possibility of producing resistant strains. ${ }^{15}$ Their antibacterial mechanisms are mostly ascribed to $\mathrm{Ag}^{+}$release, cell membrane damage, disruption of electron transport, and production of reactive oxygen species to damage bacterial DNA and proteins. ${ }^{16}$ In this section, AgNPs are used as representatives of MNPs to discuss the enhancement of the antibacterial ability of TNTs. As with drug delivery, limiting the release rate of ions can extend the duration of the antibacterial ability. Different doping methods will directly affect the release rate by determining the AgNP size, distribution, and interaction with the walls. Commonly used loading methods are reduction, magnetron sputtering, electrodeposition, and ion implantation.

The reduction method is used to reduce the $\mathrm{Ag}^{+}$to silver in the solution. The TNTs are initially immersed in the $\mathrm{Ag}^{+}$solution, the reducing agents are subsequently added, and the obtained silver is precipitated on the TNTs. By increasing the TNT dimensions, the concentration of $\mathrm{Ag}^{+}$and the reaction time can increase the loading quantity and prolong drug release. ${ }^{99}$ This reduction method is simple and economical; however, the precipitated silver is not tightly bound to TNTs and can be easily detached. ${ }^{100}$ Numerous approaches have been developed to tighten the bonds and enhance the long-term antibacterial ability. Photo-assisted deposition is a fast and uniformly distributed doping method. In this process, TNTs are immersed in a silver nitrate solution with or without methanol and subsequently irradiated with UV light to closely bind AgNPs to TNTs. ${ }^{101,102}$ Wei et al ${ }^{103}$ reported that this method allowed AgNP-loaded TNTs to maintain a $50 \%$ bactericidal rate after releasing $\mathrm{Ag}^{+}$for 50 days. Further modification may also enhance the antibacterial ability. After photo-assisted deposition, Yuan et al ${ }^{104}$ fabricated a layer of bioactive polyelectrolyte multilayer films of $\mathrm{CHI}$ and dialdehyde alginate on the surface of the AgNP-doped TNTs using the spin-associated layer-bylayer technique. This coating significantly reduced the burst release, and the contained $\mathrm{CHI}$ also exerted a synergistic effect with $\mathrm{Ag}^{+}$to enhance the antibacterial property. Polydopamine-modified TNTs (Figure 6) may also prolong the release of $\mathrm{Ag}^{+}$. Polydopamine can reduce $\mathrm{Ag}^{+}$to silver nanoparticles and act as a bonding layer to dope silver nanoparticles to TNTs. ${ }^{105}$ This doping method can effectively reduce the release rate and prolong the release of $\mathrm{Ag}^{+}$up to 28 days. $^{106-109}$ 


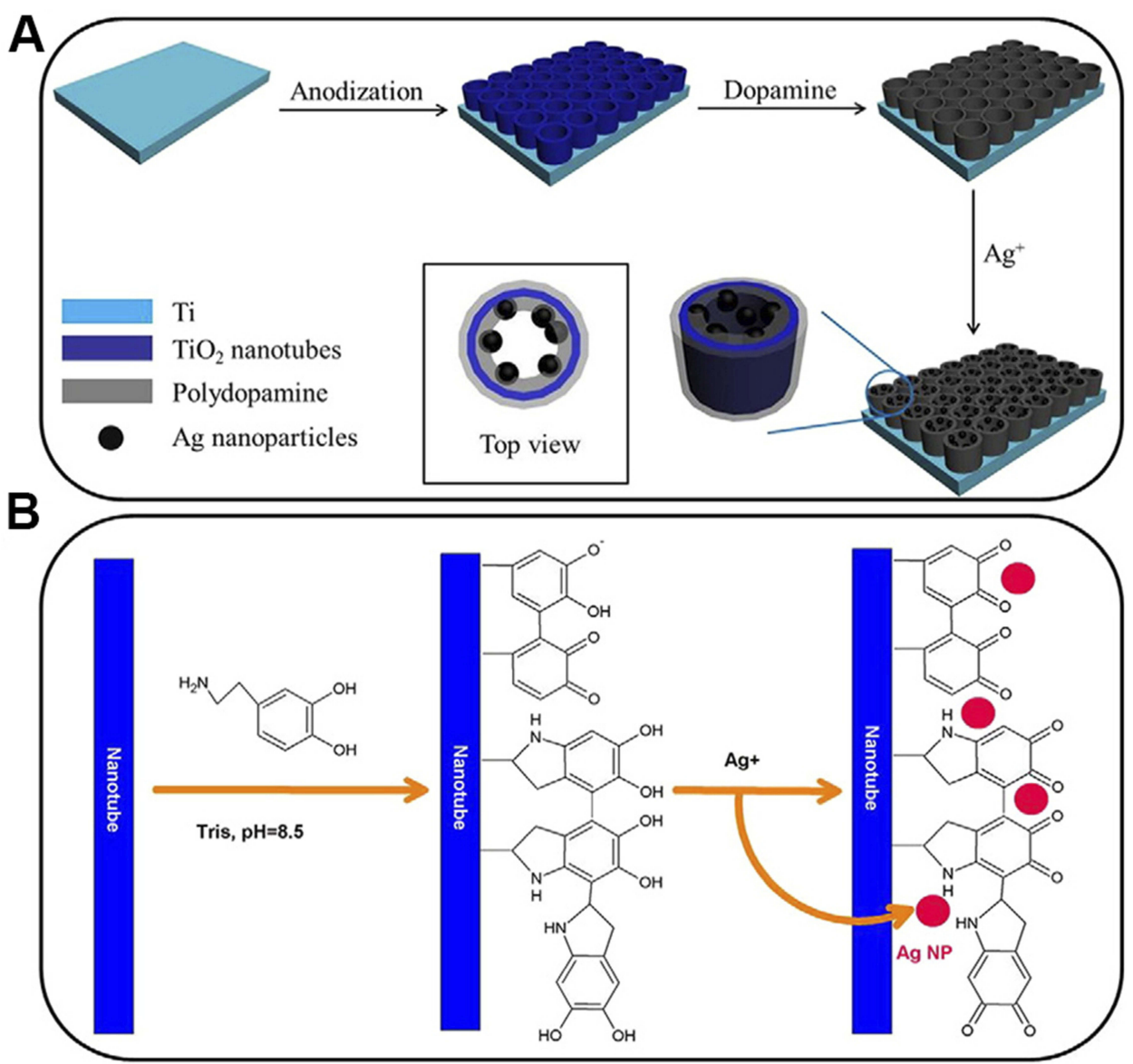

Figure 6 Schematic diagram of PDA-assisted preparation of $\mathrm{AgNP}^{-\mathrm{TiO}}{ }_{2}{ }^{105}$

Note: (A) Process for the preparation of PDA-assisted $\mathrm{AgNP}_{-} \mathrm{TiO}_{2}$. (B) The mechanism of $\mathrm{pH}$-induced dopamine self-polymerization and AgNP synthesis. Reprinted from Surf Coat Tech, 320, Xu JW, Xu N, Zhou T, et al, Polydopamine coatings embedded with silver nanoparticles on nanostructured titania for long-lasting antibacterial effects, 608-613, Copyright (2017) with permission from Elsevier.

Abbreviations: PDA, polydopamine; AgNP, silver nanoparticle.

Unlike the reduction method, ions and electrons in the magnetron sputtering method are vertically sputtered from the magnetron target materials. Therefore, AgNPs are directly formed inside the TNTs and are evenly distributed along the tubes with firm bindings. The size, distribution, and loading amount of AgNPs can vary by changing the sputtering parameters, such as input power, sputtering time, and net power. As the reaction time and input power increase, the size and loading amount of AgNPs increase, and a thin film appears on the surfaces of TNTs, resulting in massive burst release. ${ }^{100,110}$ Uhm et $\mathrm{al}^{111}$ obtained various TNTs doped with spherical AgNPs or thin Ag films by changing the time and input power under the fixed net power (Figure 7). Compared with the Ag film TNTs, TNTs with spherical AgNPs exhibited lower burst release and maintained their antibacterial ability after 60 days of sustained release. This indicated that altering the shape of AgNPs via regulation of the reaction parameters can enhance the long-term antibacterial ability.
Electrodeposition can also uniformly distribute AgNPs on TNTs. AgNP-doped TNTs obtained by pulse electrodeposition could continuously release $\mathrm{Ag}^{+}$for 4 weeks in vivo, consequently enhancing their long-term antibacterial property. ${ }^{112}$ Also, various kinds of nanoparticles can be simultaneously doped on TNTs via electrodeposition to achieve multiple biofunctions. Numerous studies have shown that silver can be doped together with hydroxyapatite or calcium phosphate by electrodeposition to exhibit both osteogenesis and antibacterial ability. Furthermore, the presence of hydroxyapatite reduces the exposure of AgNPs, thus lowering the release rate of $\mathrm{Ag}^{+}$ and further prolonging the antibacterial effect. ${ }^{73,113,114}$

AgNPs can be firmly doped on TNTs by the ion implantation method and are often distributed deeply in TNTs with very limited $\mathrm{Ag}^{+}$release. Therefore, the AgNP-doped TNTs exhibit stable, long-term contact antibacterial ability. ${ }^{98,115}$ The reaction time can change the size and distribution density of the silver nanoparticles. Longer times are associated with 


\section{A}

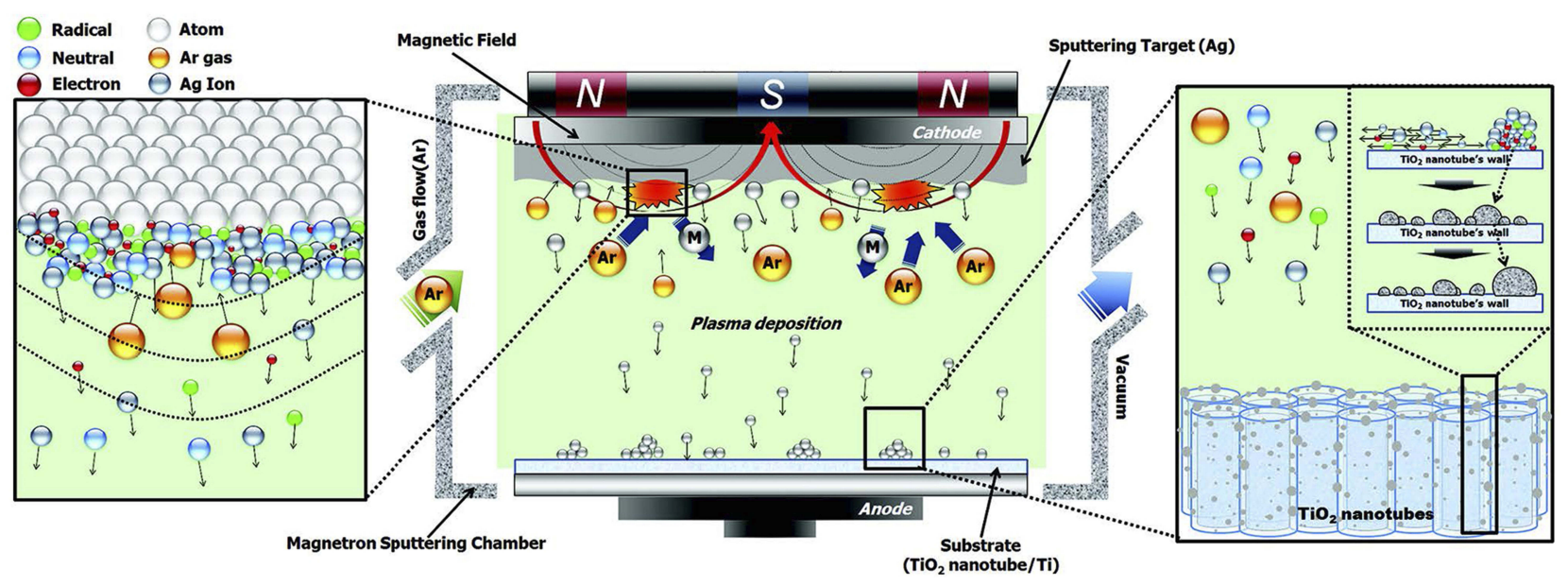

B

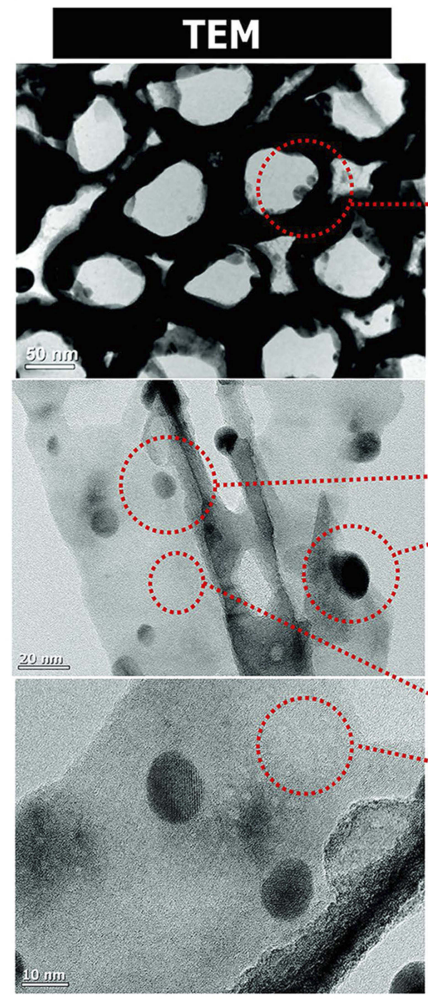

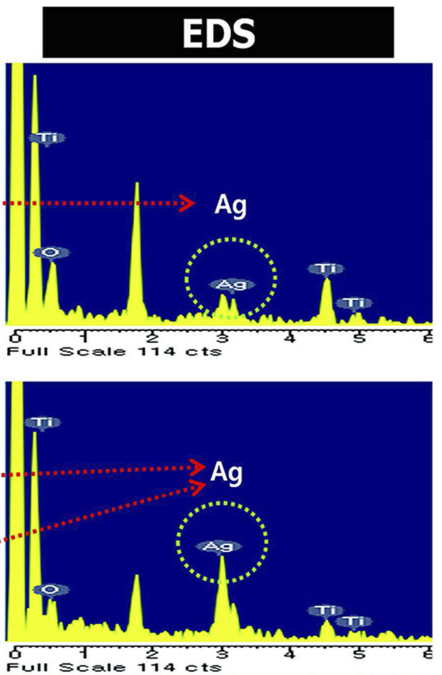



C

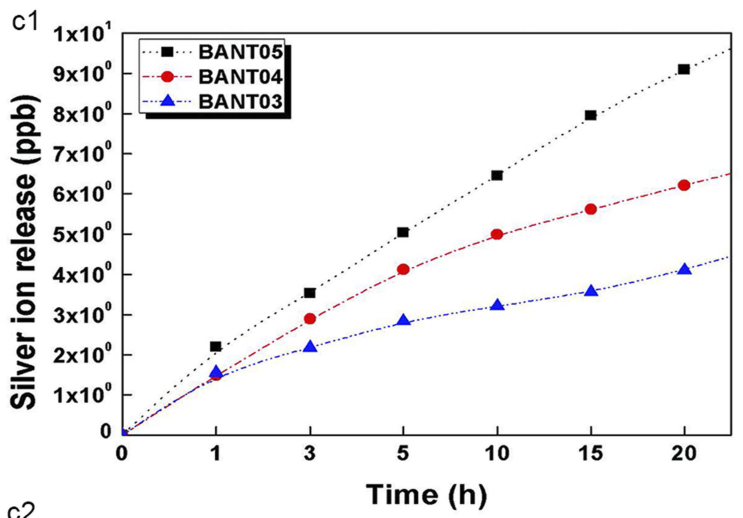

c2

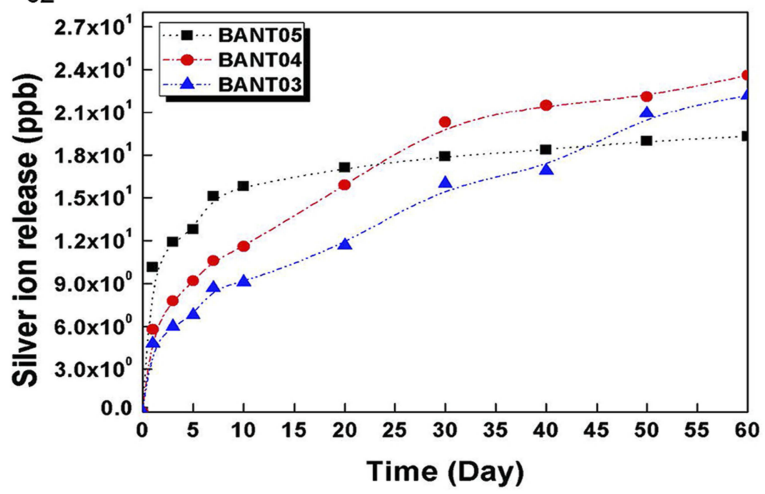

Figure 7 TNTs doped with AgNPs by magnetron sputtering showed increased antibacterial ability. "I

Note: (A) Schematic diagrams of the fabrication of AgNPs by magnetron sputtering. (B) TEM and EDS analysis of AgNPs-doped TNTs. (C) Release of Ag ${ }^{+}$from AgNPsdoped TNTs, (cl) the burst release in $20 \mathrm{hrs,} \mathrm{and} \mathrm{(c2)} \mathrm{the} \mathrm{long-term} \mathrm{release} \mathrm{(60} \mathrm{days).} \mathrm{Reproduced} \mathrm{from} \mathrm{J} \mathrm{Biomed} \mathrm{Nanotechnol,} \mathrm{Uhm} \mathrm{SH,} \mathrm{Kwon} \mathrm{JS,} \mathrm{Song} \mathrm{DH,} \mathrm{et} \mathrm{al,} \mathrm{Long-Term}$ Antibacterial Performence and Bioactivity of Plasma-Engineered Ag-NPs/TiO2 Nanotubes for Bio-Implants, 12(10):1890-1906, Copyright (2016) with permission of AMERICAN SCIENTIFIC PUBLISHERS, permission conveyed through Copyright Clearance Center, http://dx.doi.org/10.1I166/jbn.2016.23I0.

Abbreviations: AgNPs, silver nanoparticles; TEM, transmission electron microscope; EDS, energy dispersive spectrometer.

higher density, and AgNPs with extremely small or large sizes appear simultaneously. ${ }^{98}$ The voltage applied to ion implantation determines the distribution of silver inside the TNTs. The distribution of silver deepens into TNTs as the voltage increases. Although the release of $\mathrm{Ag}^{+}$is already limited, the deeper distribution further reduces the release, thus impairing the killing ability of the release. However, the contact killing of AgNP-doped TNTs is characterized by limitations. It can only kill the contact part of the bacterial layer, whereas the upper part of the bacterial and planktonic bacterial layer remains active. Wang et $\mathrm{al}^{55}$ loaded vancomycin on TNTs after ion implantation, which imparts 
AgNPs-loaded TNTs with the killing ability of the release and effectively enhanced the antibacterial effects.

\section{Doping with non-metallic elements}

Non-metallic ions can be doped on TNTs to enhance the antibacterial ability. $\mathrm{F}^{-}$are the most common non-metal ions doped on TNTs because they are usually contained in electrolytes and can be directly doped on TNTs by anodization. Therefore, it is important to understand the effect of $\mathrm{F}^{-}$ on the antibacterial function of TNTs. Several studies claimed that $\mathrm{F}^{-}$could increase the hydrophobicity of the surface to facilitate bacterial adhesion. In addition, a reduction in the $\mathrm{F}^{-}$contained in TNTs also led to a decrease in bacterial adhesion. ${ }^{116}$ On the contrary, some studies reported that $\mathrm{F}^{-}$could enhance the antibacterial ability of TNTs. The ions could bind to bacterial enzymes, interfering with the metabolism of bacteria and directly killing them. ${ }^{34,116}$ Radtke et $\mathrm{al}^{49}$ claimed that TNTs with the highest content of $\mathrm{F}^{-}$exhibited the strongest antibacterial ability. However, the antibacterial ability and possible antibacterial mechanism of $\mathrm{F}^{-}$doped TNTs remain unexplored and require further research. Other non-metallic elements have also been used with findings that are more consistent. Liu et $\mathrm{al}^{117}$ doped nitrogen ions on TNTs by ion implantation. The TNT hydrophilicity was increased, leading to improved biocompatibility and antibacterial ability. Of note, the 24 -hr antibacterial rate reached $63.1 \%$. However, this antibacterial ability is not proportional to the content of nitrogen ions. Therefore, it is impossible to obtain a stronger antibacterial property by doping more nitrogen ions. Therefore, the antibacterial effect of nitrogen is extremely limited. Carbon can also be used in the antibacterial field. Wang et $\mathrm{al}^{118}$ used graphite as a negative electrode in the anodizing process. The obtained TNTs were annealed afterward at different temperatures to obtain TNT-C with different carbon contents and capacitances. The charged TNT-C achieved a contact antibacterial effect by affecting the electron transfer of bacterial membranes, and the antibacterial ability increased in parallel with the capacitance. However, this type of antibacterial capacitance could only last for a few minutes after power turned off, and did not possess long-term antibacterial ability. At present, the antibacterial ability of TNT doped with non-metallic ions is relatively limited, and further research is warranted to explore this field.

\section{Bacterial self-responsive systems}

For antibacterial agent-loaded TNTs, the release is triggered by the difference in the concentration gradient.
Therefore, the release is initiated at the moment the TNTs are implanted, and the maximum release time is determined by the loading quantity as well as the lowest release rate required for the minimum antibacterial ability. In order to maximize the bactericidal effect with the limited loaded agents, the release should also be well controlled. During infection, the secretion of bacteria and the inflammatory response change the local environment. These environmental changes can be used to trigger the release. These modified TNTs are termed bacterial selfresponsive systems.

\section{$\mathrm{pH}$-triggered bacterial self-responsive systems}

The $\mathrm{pH}$ of infection sites will decrease because of the metabolism of bacteria, and the acidified surrounding environment is beneficial for their growth and adhesion. Therefore, the variation in $\mathrm{pH}$ can be the trigger to control the release of the antibacterial agent. ${ }^{119-121}$ Chemical bonds (eg, Schiff base bonds, ${ }^{122}$ acetal linkers, ${ }^{123}$ and coordination bonds ${ }^{124-126}$ ), which are stable under neutral conditions whereas they dissociate at lower $\mathrm{pH}$, are essential in the self-response systems. By fabricating acid-sensitive coatings or simply binding agents to TNTs via these bonds, pH-triggered release retains more agents in the neutral environment, while accelerating release in the acidified environment. Tao et $\mathrm{al}^{122}$ conjugated gentamicin with alginate dialdehyde by a Schiff bond. As the $\mathrm{pH}$ decreased, the Schiff bonds were disrupted and accelerated drug release. Xiang et $\mathrm{al}^{125}$ formed a gatekeeper coating by conjugating $\mathrm{ZnO}$ quantum dots (QDs)- $\mathrm{NH}_{2}$ with folic acid (Figure 8). This coating dissolved in the acidic environment and showed synergistic antibacterial properties by releasing zinc ions and vancomycin. Under neutral conditions, drug leakage diminished the loaded quantity and induced resistant bacteria. Zhuk et al ${ }^{120}$ reported that coatings obtained by direct assembly of tannic acid and cationic antibiotics (tobramycin, gentamicin, and polymyxin B) prevented drug release for up to 35 days in a neutral environment and reduced the burst release at lower $\mathrm{pH}$, greatly prolonging the duration of the antibacterial effect.

\section{Temperature-triggered bacterial self- responsive systems}

The occurrence of infection causes an inflammatory reaction that increases the local temperature to $>38^{\circ} \mathrm{C} .{ }^{127}$ This significant change in body temperature may be a trigger 
A

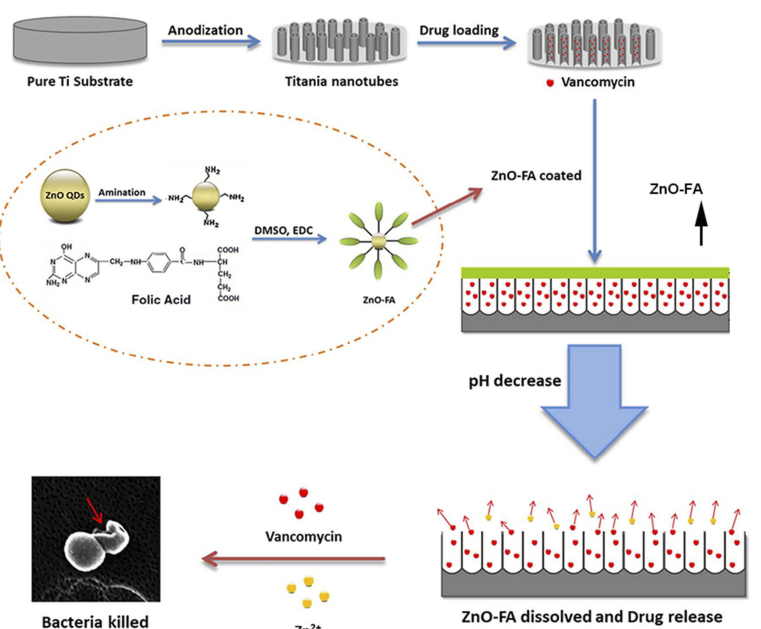

C



B
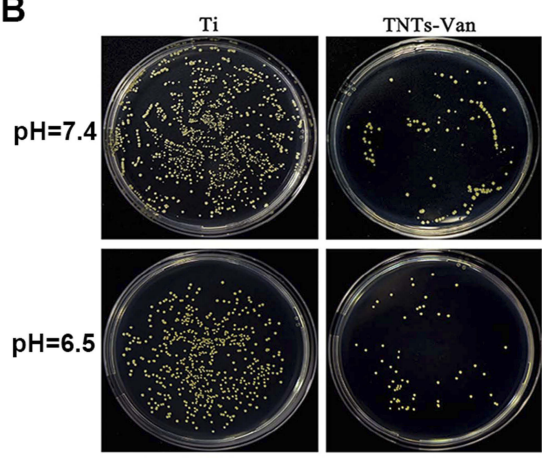

TNTs-Van@ZnO-FA
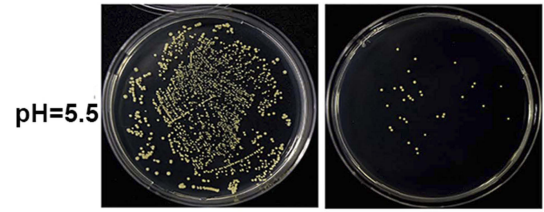

S. aureus

c2

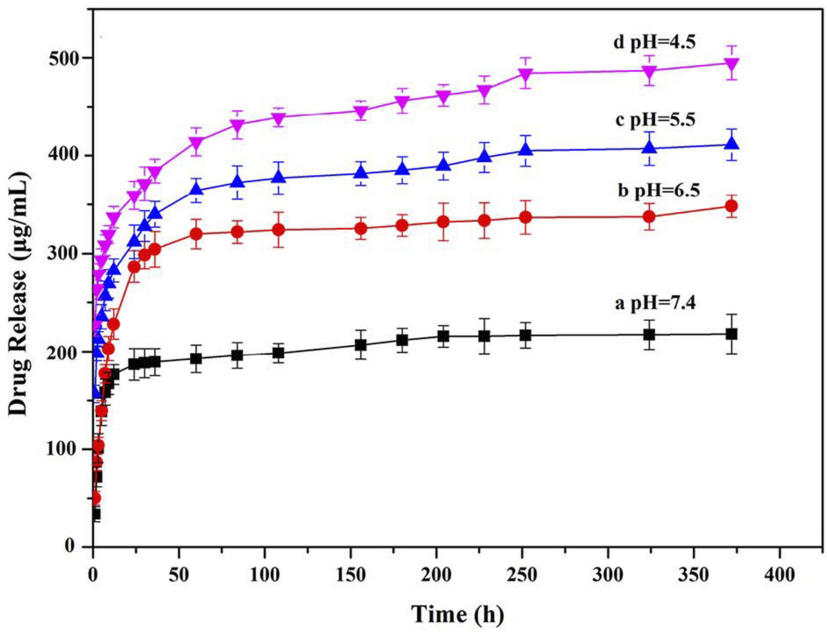

Figure 8 Schematic diagrams of the $\mathrm{pH}$-triggered self-response system. ${ }^{125}$

Note: (A) The $\mathrm{pH}$-triggered bacterial self-response system. (B) Plate images of viable $\mathrm{S}$. aureus grown on different samples after $24 \mathrm{hrs}$ of culture. (C) The release profile of the drug from the system with different $\mathrm{pH},(\mathrm{cl})$ release for $24 \mathrm{hrs}$, and (c2) release for $16 \mathrm{~d}$. Reprinted from Mat Sci Eng C-Mater, 85, Xiang YM, Liu XM, Mao CY, et al, Infection-prevention on Ti implants by controlled drug release from folic acid/ZnO quantum dots sealed titania nanotubes, 214-224, Copyright (2018) with permission from Elsevier.

Abbreviations: TNTs-Van, vancomycin-loaded TNTs; TNTs-Van@ZnO-FA, vancomycin-loaded TNTs that covered with ZnO quantum dots (QDs)-NH2 and folic acid conjugated coating; DMSO, dimethyl sulfoxide; EDC, I-(3-dimethylaminopropyl)-3-ethylcarbodiimide hydrochloride.

for the self-response system. Cai et al ${ }^{127}$ prepared a temperature-controlled release hydrogel coating using a mixture of $\mathrm{N}$-isopropylacrylamide and acrylamide (Figure 9). The results showed that approximately $70 \%$ of the drug was released at $38^{\circ} \mathrm{C}$ in 8 days. Notably, the released amount at $25^{\circ} \mathrm{C}$ was $20 \%$. The mechanism of temperature-controlled release is that the coating displays a highly water swollen state when the surrounding temperature is $<38^{\circ} \mathrm{C}$, and its volume is sufficiently large to block the opening of the TNTs and prevent drug release. When the temperature is $>38^{\circ} \mathrm{C}$, the coating displays a collapsing state and the volume is reduced. Consequently, the drug can be released from the TNTs, and the initial burst release is restricted due to the presence of the collapsing coating. Although further improvement is necessary to guarantee the elimination of the drug leakage at lower temperatures, the temperature-based self-response system shows good potential for antibacterial application.

\section{Enzyme-triggered bacterial self-responsive systems}

Enzymes produced by bacteria can also be used to trigger self-response antibacterial ability. Hyaluronic acid is an antibacterial agent and can inhibit the early stage adhesion of bacteria. Hyaluronic acid can be degraded by hyaluronidase (HAase) secreted by bacteria. ${ }^{128-130}$ Yuan et al $^{131}$ coated a 
A

a1

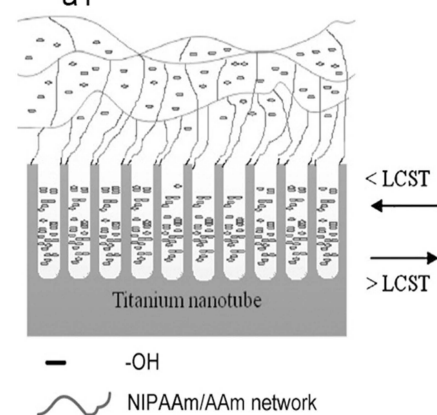

B a2

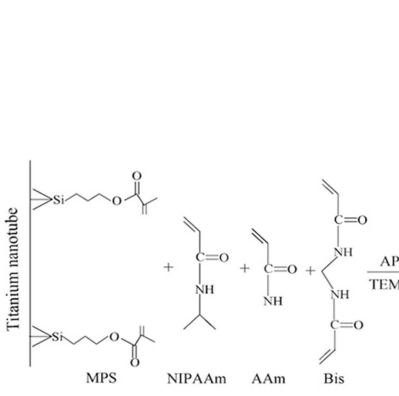

b2

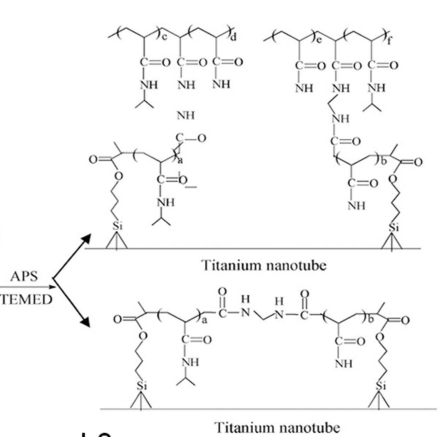

b3
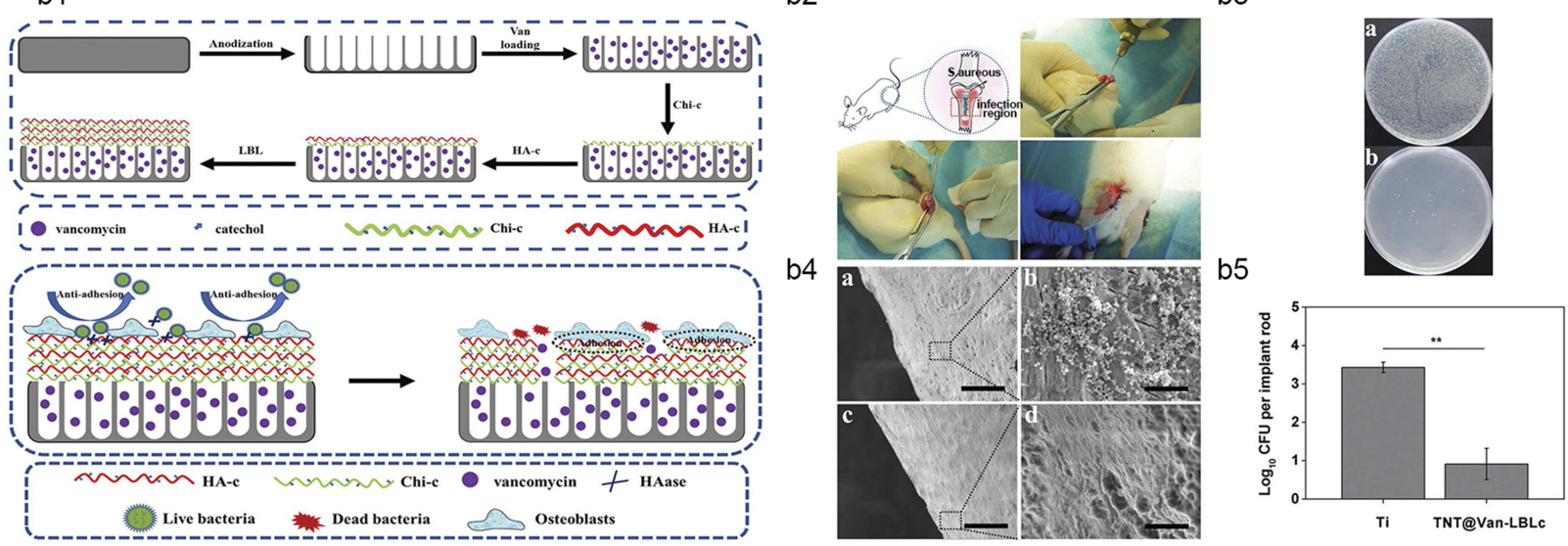

Figure 9 Schematic diagram of the temperature-triggered self-response system and enzyme-triggered self-response system. ${ }^{127,131}$

Note: (A) Schematic diagram of the temperature-triggered bacterial self-response system, ${ }^{127}$ (al) drug-loaded titanium nanotube with hydrogel coating, and (a2) scheme for the synthesis of temperature-sensitive coating. (B) Enzyme-triggered bacterial self-response system, (bl) fabrication and mechanism of the system, (b2) depiction of the implantation procedure of in an infected animal model, (b4) plate images of S. aureus detached from (A) Ti and (B) system, diluted 10 times, and cultured for 18 hrs, (b4) SEM images of bacteria adhesion, I month after implantation, ${ }^{131}$ (A) and (B) Ti, (C) and (D) TNT@-LBLc. Scale bar $=100 \mu \mathrm{m}$ for (A) and (C), scale bar $=10 \mu \mathrm{m}$ for (B) and (D), and (b5) total number of surviving bacteria, **P<0.01. (A) Reprinted from Cai KY, Jiang F, Luo Z, Chen XY, Temperature-Responsive Controlled Drug Delivery System Based on Titanium Nanotubes. Adv Eng Mater, 20 10;1 2(9):B565-B570, with permission from John Wiley and Sons. (B) Reproduced from Yuan Z, Huang SZ, Lan SX, et al. Surface engineering of titanium implants with enzymetriggered antibacterial properties and enhanced osseointegration in vivo. J Mater Chem B. 2018;6(48):8090-8104, with permission of The Royal Society of Chemistry, http://dx.doi.org/ 10.1039/c8tb01918e.

Abbreviations: LCST, lower critical solution temperature; APS, ammonium persulfate; TEMED, N,N,N',N'-tetramethylethylenediamine; S. aureus, Staphylococcus aureus; Van, vancomycin; LBL, layer by layer technique; Chi-c, chitosan-catechol; HA-c, hyaluronate-catechol; TNT@Van-LBLc, vancomycin-loaded TNTs that covered with chitosan-catechol coating via layer by layer technique.

gentamicin-loaded TNT with catechol-functionalized dopamine-modified hyaluronic acid and 3,4-dihydroxyhydrocinnamic acid-modified CHI (Figure 9). This system achieved its antibacterial ability through the dual effects of anti-adhesion and enzyme-controlled release of antibiotics. When the samples were placed in solutions with different concentrations of HAase, the release rate increased with higher concentration. Their subsequent experiments in vitro and in vivo showed that the system was sensitive to the HAase concentrations produced by bacteria and showed self-responsive antibacterial ability.

External stimuli, such as radiofrequency, magnetic field, and ultrasound may also trigger drug release. However, this delayed release does not prevent infection in time. ${ }^{10,132}$ In contrast, the self-responsive system can rapidly release antibacterial agents in the early stage of infection and has great potential for application in implants. Nevertheless, there are limitations to be overcome. Low drug concentration, as the result of sustained release in a non-bacteria environment, consumes drug reserves and increases the possibility of developing drug-resistant bacteria. Therefore, it is essential to eliminate drug leakage during non-infection periods. In addition, implants may be challenged by infections multiple times; hence, one-time drug release is insufficient. The ideal drug release should be terminated after the infection is eliminated until the subsequent stimulus occurs. In summary, TNT platforms that possess self-responsive antibacterial ability with multiple release are the direction for future research.

\section{Perspectives}

Fabrication methods are important for the exploration of the application of materials. Larger dimensions have consistently 
been the goal throughout the development of TNT fabrication. The precise regulation of morphological parameters, such as tube gaps, wall thickness, and crystal forms, cannot be simultaneously achieved. This greatly hinders the exploration of the optimal morphology for biocompatibility and antibacterial ability. Therefore, the fabrication method should also focus on the precise details. Further research for the improvement of antibacterial ability should focus on enhancing the long-term bactericidal ability and reducing toxicity. The TNT morphology should be explored to maximize its antibacterial properties by achieving the optimal balance between the contact antibacterial property and control of drug release. In addition, coatings should be characterized by improved immunocompatibility and less toxicity. Additionally, the suitable thickness and degrading rate of coatings should be investigated for better control of release. Furthermore, the self-response system should be more sensitive to infection indicators. Leakage of the antibacterial agent during non-infection periods must be terminated to fortify the long-term antibacterial property of the structure. When the bacteria are eliminated, the drug release should be arrested until the subsequent infection occurs. This will ensure multiple releases during the long-term prosthesis treatment. Different infection indicators, such as other enzymes secreted by bacteria, may also be considered as targets of the self-response system. Furthermore, the development of multiple-release self-response systems obtained by combining release-control structures and bacterial-sensitive coatings will be an important advancement in antibacterial application.

For the clinical application of these structures, further systematic research studies are required to measure and strengthen the biocompatibility, reduce long-term toxicity and wear resistance, and prolong the duration of the antibacterial ability and longevity. Finally, more animal research studies are warranted prior to conducting clinical trials.

\section{Conclusion}

At present, the prevention and treatment of postoperative prosthesis infection remain a clinical challenge. Fortunately, the emergence and development of TNTs provide a possible solution. With the fabrication advancement, large-sized and complex-structured TNTs have been manufactured with the ability to carry drugs and control their release. Bare TNTs show convincing antibacterial properties and the optimal antibacterial diameter remains to be determined. Reducing burst release and toxicity is critical for the release-killing antibacterial ability. Coatings with intrinsic antibacterial ability and appropriate thickness can achieve an ideal antibacterial effect. Moreover, doping methods determine the distribution and release of nanoparticles. Combining doping methods with special structures or coatings can further enhance long-term antibacterial ability. Chemical bonds and coatings sensitive to bacterial stimuli can be combined with TNTs, these selfresponse systems can automatically respond to infection in the early stage. Future research should focus on enhancing the long-term antibacterial properties, especially the control of antibacterial agent release.

\section{Acknowledgment}

The work was supported by the National Natural Science Foundation of China (Grant No. 81772456, 51627805).

\section{Disclosure}

The authors declare that they have no competing interests in this work.

\section{References}

1. Lee K, Goodman SB. Current state and future of joint replacements in the hip and knee. Expert Rev Med Devices. 2008;5(3):383-393. doi:10.1586/17434440.5.3.383

2. Agarwal R, Garcia AJ. Biomaterial strategies for engineering implants for enhanced osseointegration and bone repair. Adv Drug Deliver Rev. 2015;94:53-62. doi:10.1016/j.addr.2015.03.013

3. Barfeie A, Wilson J, Rees J. Implant surface characteristics and their effect on osseointegration. Brit Dent J. 2015;218:5. doi:10.1038/sj.bdj.2015.171

4. Oliveira WF, Arruda IRS, Silva GMM, Machado G, Coelho LCBB, Correia MTS. Functionalization of titanium dioxide nanotubes with biomolecules for biomedical applications. Mat Sci Eng C-Mater. 2017;81:597-606. doi:10.1016/j.msec.2017.08.017

5. Feng WC, Geng Z, Li ZY, et al. Controlled release behaviour and antibacterial effects of antibiotic-loaded titania nanotubes. Mat Sci Eng C-Mater. 2016;62:105-112. doi:10.1016/j.msec.2016.01.046

6. Peng Z, Ni J, Zheng K, et al. Dual effects and mechanism of TiO2 nanotube arrays in reducing bacterial colonization and enhancing C3H10T1/2 cell adhesion. Int J Nanomedicine. 2013;8:3093-3105. doi:10.2147/IJN.S48084

7. Jacqueline C, Caillon J. Impact of bacterial biofilm on the treatment of prosthetic joint infections. J Antimicrob Chemoth. 2014;69:3740. doi: $10.1093 / \mathrm{jac} / \mathrm{dku} 254$

8. Rabin N, Zheng Y, Opoku-Temeng C, Du YX, Bonsu E, Sintim HO. Biofilm formation mechanisms and targets for developing antibiofilm agents (vol 7, pg 493, 2015). Future Med Chem. 2015;7(10):1362. doi: $10.4155 / \mathrm{fmc} .15 .77$

9. Abad CL, Haleem A. Prosthetic joint infections: an update. Curr Infect Dis Rep. 2018;20(7):15. doi:10.1007/s11908-018-0622-0

10. Wang Q, Huang JY, Li HQ, et al. Recent advances on smart TiO2 nanotube platforms for sustainable drug delivery applications. Int $J$ Nanomed. 2017;12:151-165. doi:10.2147/Ijn.S117498

11. Chouirfa H, Bouloussa H, Migonney V, Falentin-Daudre C. Review of titanium surface modification techniques and coatings for antibacterial applications. Acta Biomater. 2019;83:37-54. doi:10.1016/ j.actbio.2018.10.036 
12. Gulati K, Ivanovski S. Dental implants modified with drug releasing titania nanotubes: therapeutic potential and developmental challenges. Expert Opin Drug Del. 2017;14(8):1009-1024. doi:10.1080/17425247.2017.1266332

13. Yavari SA, Chai YC, Bottger AJ, et al. Effects of anodizing parameters and heat treatment on nanotopographical features, bioactivity, and cell culture response of additively manufactured porous titanium. Mat Sci Eng C-Mater. 2015;51:132-138. doi:10.1016/j.msec.2015.02.050

14. Khudhair D, Bhatti A, Li Y, et al. Anodization parameters influencing the morphology and electrical properties of $\mathrm{TiO} 2$ nanotubes for living cell interfacing and investigations. Mat Sci Eng C-Mater. 2016;59:1125-1142. doi:10.1016/j.msec.2015.10.042

15. Huo KF, Gao B, Fu JJ, Zhao LZ, Chu PK. Fabrication, modification, and biomedical applications of anodized $\mathrm{TiO} 2$ nanotube arrays. RSC Adv. 2014;4(33):17300-17324. doi:10.1039/C4RA01458H

16. Baranwal A, Srivastava A, Kumar P, Bajpai VK, Maurya PK, Chandra P. Prospects of nanostructure materials and their composites as antimicrobial agents. Front Microbiol. 2018;9. doi:10.3389/Fmicb.2018. 00422.

17. Luan YF, Liu SD, Pihl M, et al. Bacterial interactions with nanostructured surfaces. Curr Opin Colloid In. 2018;38:170-189. doi:10.1016/j.cocis.2018.10.007

18. Li XL. Bactericidal mechanism of nanopatterned surfaces. Phys Chem Chem Phys. 2016;18(2):1311-1316. doi:10.1039/c5cp05646b

19. Wang Q, Huang JY, Li HQ, et al. TiO2 nanotube platforms for smart drug delivery: a review. Int J Nanomed. 2016;11:4819-4834. doi:10.2147/IJN.S108847

20. Noman MT, Ashraf MA, Ali A. Synthesis and applications of nanoTiO2: a review. Environ Sci Pollut R. 2019;26(4):3262-3291. doi:10.1007/s11356-018-3884-z

21. Faraji M, Mohaghegh N, Abedini A. Ternary composite of TiO2 nanotubes/Ti plates modified by g-C $3 \mathrm{~N} 4$ and $\mathrm{SnO} 2$ with enhanced photocatalytic activity for enhancing antibacterial and photocatalytic activity. J Photochem Photobiol B Biol. 2018;178:124-132. doi:10.1016/j.jphotobiol.2017.11.009

22. Nair M, Elizabeth E. Applications of titania nanotubes in bone biology. J Nanosci Nanotechno. 2015;15(2):939-955. doi:10.11 66/jnn.2015.9771

23. Roy P, Berger S, Schmuki P. TiO2 nanotubes: synthesis and applications. Angew Chem Int Edit. 2011;50(13):2904-2939.

24. Macak JM, Tsuchiya H, Ghicov A, et al. TiO2 nanotubes: selforganized electrochemical formation, properties and applications. Curr Opin Solid St M. 2007;11(1-2):3-18. doi:10.1016/j. cossms.2007.08.004

25. Gibran K, Ibadurrahman M. Effect of electrolyte type on the morphology and crystallinity of $\mathrm{TiO} 2$ nanotubes from Ti-6Al-4V anodization. Iop C Ser Earth Env. 2018;105:012038.

26. Gong D, Grimes CA, Varghese OK, et al. Titanium oxide nanotube arrays prepared by anodic oxidation. J Mater Res. 2001;16 (12):3331-3334. doi:10.1557/JMR.2001.0457

27. Lai YK, Gao XF, Zhuang HF, Huang JY, Lin CJ, Jiang L. Designing superhydrophobic porous nanostructures with tunable water adhesion Adv Mater. 2009;21(37):3799-3803. doi:10.1002/adma.v21:37

28. Macak JM, Tsuchiya H, Schmuki P. High-aspect-ratio TiO2 nanotubes by anodization of titanium. Angew Chem Int Edit. 2005;44 (14):2100-2102. doi:10.1002/anie.200462459

29. Macak JM, Sirotna K, Schmuki P. Self-organized porous titanium oxide prepared in $\mathrm{Na} 2 \mathrm{SO} 4 / \mathrm{NaF}$ electrolytes. Electrochim Acta. 2005;50(18):3679-3684. doi:10.1016/j.electacta.2005.01.014

30. Cheong YL, Yam FK, Ng SW, Hassan Z, Ng SS, Low IM. Fabrication of titanium dioxide nanotubes in fluoride-free electrolyte via rapid breakdown anodization. J Porous Mat. 2015;22 (6):1437-1444. doi:10.1007/s10934-015-0024-8

31. Macak JM, Tsuchiya H, Taveira L, Aldabergerova S, Schmuki P. Smooth anodic TiO2 nanotubes. Angew Chem Int Edit. 2005;44 (45):7463-7465. doi:10.1002/anie.200502781
32. Paulose M, Peng L, Popat KC, et al. Fabrication of mechanically robust, large area, polycrystalline nanotubular/porous $\mathrm{TiO} 2 \mathrm{mem}-$ branes. J Membrane Sci. 2008;319(1-2):199-205. doi:10.1016/j. memsci.2008.03.050

33. Richter C, Wu Z, Panaitescu E, Willey RJ, Menon L. Ultrahighaspect-ratio titania nanotubes. Adv Mater. 2007;19(7):946. doi:10. 1002/adma.200602389

34. Arita NK, Shinonaga Y, Nishino M. Plasma-based fluorine ion implantation into dental materials for inhibition of bacterial adhesion. Dent Mater J. 2006;25(4):684-692.

35. Shinonaga Y, Arita K. Antibacterial effect of acrylic dental devices after surface modification by fluorine and silver dual-ion implantation. Acta Biomater. 2012;8(3):1388-1393. doi:10.1016/j.actbio.20 11.09 .017

36. Kurtz SM, Ong KL, Lau E, Bozic KJ, Berry D, Parvizi J. Prosthetic joint infection risk after TKA in the medicare population. Clin Orthop Relat Res. 2010;468(1):52-56. doi:10.1007/s11999-0091013-5

37. Pulido L, Ghanem E, Joshi A, Purtill JJ, Parvizi J. Periprosthetic joint infection: the incidence, timing, and predisposing factors. Clin Orthop Relat Res. 2008;466(7):1710-1715. doi:10.1007/s11999008-0209-4

38. Yang Y, Ao HY, Yang SB, et al. In vivo evaluation of the antiinfection potential of gentamicin-loaded nanotubes on titania implants. Int J Nanomed. 2016;11:2223-2234.

39. Sun L, Xu JL, Sun ZH, et al. Decreased porphyromonas gingivalis adhesion and improved biocompatibility on tetracycline-loaded TiO2 nanotubes: an in vitro study. Int J Nanomed. 2018;13:67696777. doi:10.2147/IJN.S175865

40. Ivanova EP, Truong VK, Wang JY, et al. Impact of nanoscale roughness of titanium thin film surfaces on bacterial retention. Langmuir. 2010;26(3):1973-1982. doi:10.1021/la902623c

41. Awad NK, Edwards SL, Morsi YS. A review of TiO2 NTs on Ti metal: electrochemical synthesis, functionalization and potential use as bone implants. Mat Sci Eng C-Mater. 2017;76:1401-1412. doi:10.1016/j.msec.2017.02.150

42. Deng Y, Sun MZ, Shaevitz JW. Measuring peptidoglycan elasticity and stress-stiffening of live bacterial cells. Biophys J. 2011;100 (3):514-515. doi:10.1016/j.bpj.2010.12.3012

43. Pogodin S, Hasan J, Baulin VA, et al. Biophysical model of bacterial cell interactions with nanopatterned cicada wing surfaces. Biophys J. 2013;104(4):835-840. doi:10.1016/j.bpj.2012. 12.046

44. Mediaswanti K. Influence of physicochemical aspects of substratum nanosurface on bacterial attachment for bone implant applications. J Nanotechnol. 2016. doi:10.1155/2016/5026184

45. Atefyekta S, Ercan B, Karlsson J, et al. Antimicrobial performance of mesoporous titania thin films: role of pore size, hydrophobicity, and antibiotic release. Int J Nanomed. 2016;11:977-990.

46. Simi VS, Rajendran N. Influence of tunable diameter on the electrochemical behavior and antibacterial activity of titania nanotube arrays for biomedical applications. Mater Charact. 2017;129:6779. doi:10.1016/j.matchar.2017.04.019

47. Su EP, Justin DE, Pratt CR, et al. Effects of titanium nanotubes on the osseointegration, cell differentiation, mineralisation and antibacterial properties of orthopaedic implant surfaces. Bone Joint J. 2018;100B(1):9-16. doi:10.1302/0301-620X.100B1.BJJ-2017-055 1.R1

48. Mitik-Dineva N, Wang J, Truong VK, et al. Escherichia coli, pseudomonas aeruginosa, and staphylococcus aureus attachment patterns on glass surfaces with nanoscale roughness. Curr Microbiol. 2009;58(3):268-273. doi:10.1007/s00284-008-9320-8

49. Radtke A, Topolski A, Jedrzejewski T, et al. The bioactivity and photocatalytic properties of titania nanotube coatings produced with the use of the low-potential anodization of Ti6A14V alloy surface. Nanomaterials. 2017;7:8. doi:10.3390/nano7120458 
50. Lewandowska Z, Piszczek P, Radtke A, Jedrzejewski T, Kozak W, Sadowska B. The evaluation of the impact of titania nanotube covers morphology and crystal phase on their biological properties. J Mater Sci-Mater M. 2015;26:4. doi:10.1007/s10856-015-5495-2

51. Shi XG, Xu QA, Tian A, et al. Antibacterial activities of $\mathrm{TiO} 2$ nanotubes on porphyromonas gingivalis. RSC Adv. 2015;5 (43):34237-34242. doi:10.1039/C5RA00804B

52. Pawlik A, Jarosz M, Syrek K, Sulka GD. Co-delivery of ibuprofen and gentamicin from nanoporous anodic titanium dioxide layers. Colloids Surf B Biointerfaces. 2017;152:95-102. doi:10.1016/j. colsurfb.2017.01.011

53. Liu DH, He CR, Liu ZT, Xu WD. Gentamicin coating of nanotubular anodized titanium implant reduces implant-related osteomyelitis and enhances bone biocompatibility in rabbits. Int J Nanomed. 2017;12:5461-5471. doi:10.2147/IJN.S137137

54. Aguilera-Correa JJ, Doadrio AL, Conde A, et al. Antibiotic release from F-doped nanotubular oxide layer on TI6AL4V alloy to decrease bacterial viability. J Mater Sci Mater Med. 2018;29 (8):118. doi:10.1007/s10856-018-6119-4

55. Wang JX, Li JH, Qian S, et al. Antibacterial surface design of titanium-based biomaterials for enhanced bacteria-killing and cell-assisting functions against periprosthetic joint infection. Acs Appl Mater Inter. 2016;8(17):11162-11178. doi:10.1021/acsami.6b02803

56. Rudramurthy GR, Swamy MK, Sinniah UR, Ghasemzadeh A. Nanoparticles: alternatives against drug-resistant pathogenic microbes. Molecules. 2016;21:7. doi:10.3390/molecules21070836

57. Zhu C, Zhang WW, Fang SY, et al. Antibiotic peptide-modified nanostructured titanium surface for enhancing bactericidal property. J Mater Sci. 2018;53(8):5891-5908. doi:10.1007/s10853017-1669-2

58. Li T, Wang N, Chen S, Lu R, Li HY, Zhang ZT. Antibacterial activity and cytocompatibility of an implant coating consisting of $\mathrm{TiO} 2$ nanotubes combined with a GL13K antimicrobial peptide. Int J Nanomed. 2017;12:2995-3007. doi:10.2147/IJN.S128775

59. Lin WT, Tan HL, Duan ZL, et al. Inhibited bacterial biofilm formation and improved osteogenic activity on gentamicin-loaded titania nanotubes with various diameters. Int $J$ Nanomed. 2014;9:1213-1228.

60. Caliskan N, Bayram C, Erdal E, Karahaliloglu Z, Denkbas EB. Titania nanotubes with adjustable dimensions for drug reservoir sites and enhanced cell adhesion. Mater Sci Eng C Mater Biol Appl. 2014;35:100-105. doi:10.1016/j.msec.2013.10.033

61. Huang L, Chen J, Li XF, et al. Polymethacrylic acid encapsulated $\mathrm{TiO} 2$ nanotubes for sustained drug release and enhanced antibacterial activities. New J Chem. 2019;43(4):1827-1837. doi:10.1039/ C8NJ04568B

62. Zhang T, Liu Y, Zhang FF, Xiao XF. Polylysine-modified titania nanotube arrays for local drug delivery. Micro Nano Lett. 2018;13 (1):93-95. doi:10.1049/mnl.2017.0312

63. Hamlekhan A, Sinha-Ray S, Takoudis C, et al. Fabrication of drug eluting implants: study of drug release mechanism from titanium dioxide nanotubes. J Phys D Appl Phys. 2015;48:27. doi:10.1088/ 0022-3727/48/27/275401

64. Peng LL, Mendelsohn AD, LaTempa TJ, Yoriya S, Grimes CA, Desai TA. Long-term small molecule and protein elution from TiO2 nanotubes. Nano Lett. 2009;9(5):1932-1936. doi:10.1021/ n19001052

65. Shi LH, Xu H, Liao XM, et al. Fabrication of two-layer nanotubes with the pear-like structure by an in-situ voltage up anodization and the application as a drug delivery platform. J Alloy Compd. 2015;647:590-595. doi:10.1016/j.jallcom.2015.06.015

66. Zhang Y, Lan Z, Bo L, Yong H. Enhancement in sustained release of antimicrobial peptide from dual-diameter-structured $\mathrm{TiO} 2$ nanotubes for long-lasting antibacterial activity and cytocompatibility. Acs Appl Mater Inter. 2017;9(11):9449-9461. doi:10.1021/acsami. $7 \mathrm{~b} 00322$
67. Gulati K, Kant K, Findlay D, Losic D. Periodically tailored titania nanotubes for enhanced drug loading and releasing performances. $J$ Mater Chem B. 2015;3(12):2553-2559. doi:10.1039/C4TB01882F

68. Simovic S, Losic D, Vasilev K. Controlled drug release from porous materials by plasma polymer deposition. Chem Commun (Camb). 2010;46(8):1317-1319. doi:10.1039/b919840g

69. Kazek-Kesik A, Nosol A, Plonka J, et al. PLGA-amoxicillin-loaded layer formed on anodized $\mathrm{Ti}$ alloy as a hybrid material for dental implant applications. Mat Sci Eng C-Mater. 2019;94:998-1008. doi:10.1016/j.msec.2018.10.049

70. Sun SJ, Zhang YL, Zeng DL, Zhang SM, Zhang FQ, Yu WQ. PLGA film/Titanium nanotubues as a sustained growth factor releasing system for dental implants. $J$ Mater Sci-Mater $M$. 2018;29:9. doi:10.1007/s10856-018-6138-1

71. Wang TT, Weng ZY, Liu XM, Yeung KWK, Pan HB, Wu SL. Controlled release and biocompatibility of polymer/titania nanotube array system on titanium implants. Bioact Mater. 2017;2 (1):44-50. doi:10.1016/j.bioactmat.2017.02.001

72. Shen J, Jin B, Qi YC, Jiang QY, Gao XF. Carboxylated chitosan/ silver-hydroxyapatite hybrid microspheres with improved antibacterial activity and cytocompatibility. Mat Sci Eng C-Mater. 2017;78:589-597. doi:10.1016/j.msec.2017.03.100

73. Yan YJ, Zhang XJ, Huang Y, Ding QQ, Pang XF. Antibacterial and bioactivity of silver substituted hydroxyapatite/TiO2 nanotube composite coatings on titanium. Appl Surf Sci. 2014;314:348357. doi:10.1016/j.apsusc.2014.07.027

74. $\mathrm{Hu} \mathrm{X}, \mathrm{Xu} \mathrm{R}, \mathrm{Yu} \mathrm{X}$, et al. Enhanced antibacterial efficacy of selective laser melting titanium surface with nanophase calcium phosphate embedded to TiO2 nanotubes. Biomed Mater. 2018;13 (4):045015. doi:10.1088/1748-605X/aac1a3

75. Lin WT, Zhang YY, Tan HL, et al. Inhibited bacterial adhesion and biofilm formation on quaternized chitosan-loaded titania nanotubes with various diameters. Materials. 2016;9:3. doi:10.3390/ma9030155

76. Liu P, Hao YS, Zhao YC, Yuan Z, Ding Y, Cai KY. Surface modification of titanium substrates for enhanced osteogenetic and antibacterial properties. Colloid Surf B. 2017;160:110-116. doi:10.1016/j.colsurfb.2017.08.044

77. Mokhtari H, Ghasemi Z, Kharaziha M, Karimzadeh F, Alihosseini F. Chitosan-58S bioactive glass nanocomposite coatings on $\mathrm{TiO} 2$ nanotube: structural and biological properties. Appl Surf Sci. 2018;441:138-149. doi:10.1016/j.apsusc.2018.01.314

78. Sallem F, Boudon J, Heintz O, Severin I, Megriche A, Millot N. Synthesis and characterization of chitosan-coated titanate nanotubes: towards a new safe nanocarrier. Dalton T. 2017;46 (44):15386-15398. doi:10.1039/C7DT03029K

79. Mohan L, Anandan C, Rajendran N. Drug release characteristics of quercetin-loaded $\mathrm{TiO} 2$ nanotubes coated with chitosan. Int $J$ Biol Macromol. 2016;93:1633-1638. doi:10.1016/j.ijbiomac.2016.04.034

80. Rapoport N, Pitt WG, Sun H, Nelson JL. Drug delivery in polymeric micelles: from in vitro to in vivo. $J$ Control Release. 2003;91 (1-2):85-95.

81. Aw MS, Addai-Mensah J, Losic D. A multi-drug delivery system with sequential release using titania nanotube arrays. Chem Commun. 2012;48(27):3348-3350. doi:10.1039/c2cc17690d

82. Aw MS, Simovic S, Addai-Mensah J, Losic D. Polymeric micelles in porous and nanotubular implants as a new system for extended delivery of poorly soluble drugs. J Mater Chem. 2011;21 (20):7082-7089. doi:10.1039/c0jm04307a

83. Shanmuganathan R, MubarakAli D, Prabakar D, et al. An enhancement of antimicrobial efficacy of biogenic and ceftriaxone-conjugated silver nanoparticles: green approach. Environ Sci Pollut Res Int. 2018;25(11):10362-10370. doi:10.1007/s11356-017-9367-9

84. Zhang YX, Dong CF, Yang SF, et al. Enhanced silver loaded antibacterial titanium implant coating with novel hierarchical effect. J Biomater Appl. 2018;32(9):1289-1299. doi:10.1177/ 0885328218755538 
85. Ulfahl IA, Bachtiar BM, Murnandityas AR. Synthesis and characterization of Ag-Doped TiO2 nanotubes on Ti-6A1-4V and Ti-6A17Nb alloy. AIP Conf Proc. 2018;1964:020008.

86. Pugazhendhi A, Prabakar D, Jacob JM, Karuppusamy I, Saratale RG. Synthesis and characterization of silver nanoparticles using Gelidium amansii and its antimicrobial property against various pathogenic bacteria. Microb Pathog. 2018;114:41-45. doi:10.1016/j.micpath.2017.11.013

87. Saravanan M, Arokiyaraj S, Lakshmi T, Pugazhendhi A. Synthesis of silver nanoparticles from Phenerochaete chrysosporium (MTCC787) and their antibacterial activity against human pathogenic bacteria. Microb Pathog. 2018;117:68-72. doi:10.1016/j.micpath.2018. 02.008

88. Suganthy N, Sri Ramkumar V, Pugazhendhi A, Benelli G, Archunan G. Biogenic synthesis of gold nanoparticles from Terminalia arjuna bark extract: assessment of safety aspects and neuroprotective potential via antioxidant, anticholinesterase, and antiamyloidogenic effects. Environ Sci Pollut Res Int. 2018;25 (11):10418-10433. doi:10.1007/s11356-017-9789-4

89. Wang GM, Feng HQ, Jin WH, et al. Long-term antibacterial characteristics and cytocompatibility of titania nanotubes loaded with $\mathrm{Au}$ nanoparticles without photocatalytic effects. Appl Surf Sci. 2017;414:230-237. doi:10.1016/j.apsusc.2017.04.053

90. Murphin Kumar PS, MubarakAli D, Saratale RG, et al. Synthesis of nano-cuboidal gold particles for effective antimicrobial property against clinical human pathogens. Microb Pathog. 2017;113:68-73. doi:10.1016/j.micpath.2017.10.032

91. Srinivasan M, Venkatesan M, Arumugam V, et al. Green synthesis and characterization of titanium dioxide nanoparticles (TiO2 NPs) using Sesbania grandiflora and evaluation of toxicity in zebrafish embryos. Process Biochem. 2019;80:197-202. doi:10.1016/j. procbio.2019.02.010

92. Vasantharaj S, Sathiyavimal S, Senthilkumar P, LewisOscar F, Pugazhendhi A. Biosynthesis of iron oxide nanoparticles using leaf extract of Ruellia tuberosa: antimicrobial properties and their applications in photocatalytic degradation. J Photochem Photobiol B Biol. 2019;192:74-82. doi:10.1016/j.jphotobiol.2018.12.025

93. Pugazhendhi A, Prabhu R, Muruganantham K, Shanmuganathan R, Natarajan S. Anticancer, antimicrobial and photocatalytic activities of green synthesized magnesium oxide nanoparticles (MgONPs) using aqueous extract of Sargassum wightii. J Photochem Photobiol B Biol. 2019;190:86-97. doi:10.1016/j.jphotobiol.2018.11.014

94. Pugazhendhi A, Kumar SS, Manikandan M, Saravanan M. Photocatalytic properties and antimicrobial efficacy of $\mathrm{Fe}$ doped $\mathrm{CuO}$ nanoparticles against the pathogenic bacteria and fungi. Microb Pathog. 2018;122:84-89. doi:10.1016/j.micpath.2018.06.016

95. Fathima JB, Pugazhendhi A, Venis R. Synthesis and characterization of $\mathrm{ZrO} 2$ nanoparticles-antimicrobial activity and their prospective role in dental care. Microb Pathog. 2017;110:245-251. doi:10.1016/j.micpath.2017.06.039

96. Vassallo J, Besinis A, Boden R, Handy RD. The minimum inhibitory concentration (MIC) assay with Escherichia coil: an early tier in the environmental hazard assessment of nanomaterials? Ecotoxicol Environ Saf. 2018;162:633-646. doi:10.1016/j.ecoenv.2018.06.085

97. Shuai CJ, Shuai CY, Feng P, Gao CD, Peng SP, Yang YW. Antibacterial capability, physicochemical properties, and biocompatibility of $\mathrm{nTiO}(2)$ incorporated polymeric scaffolds. PolymersBasel. 2018;10:3.

98. Zhu Y, Cao HL, Qiao SC, et al. Hierarchical micro/nanostructured titanium with balanced actions to bacterial and mammalian cells for dental implants. Int J Nanomed. 2015;10:6659-6674. doi:10.2147/ IJN.S92110

99. Yavari SA, Loozen L, Paganelli FL, et al. Antibacterial behavior of additively manufactured porous titanium with nanotubular surfaces releasing silver ions. Acs Appl Mater Inter. 2016;8(27):1708017089. doi:10.1021/acsami.6b03152
100. Uhm SH, Song DH, Kwon JS, Lee SB, Han JG, Kim KN. Tailoring of antibacterial $\mathrm{Ag}$ nanostructures on $\mathrm{TiO} 2$ nanotube layers by magnetron sputtering. J Biomed Mater Res B. 2014;102(3):592603. doi:10.1002/jbm.b.33038

101. Tian T. Preparation and antibacterial bioactivity of Ti-base titania nanotube arrays. Key Eng Mater. 2014;609-610:435-441. doi:10.4028/www.scientific.net/KEM.609-610.435

102. Li GZ, Zhao QM, Yang HL, Cheng L. Antibacterial and microstructure properties of titanium surfaces modified with Ag-incorporated nanotube arrays. Mater Res-Ibero-Am J. 2016;19(3):735-740.

103. Wei LY, Wang HF, Wang ZQ, Yu MY, Chen SG. Preparation and long-term antibacterial activity of $\mathrm{TiO} 2$ nanotubes loaded with $\mathrm{Ag}$ nanoparticles and Ag ions. RSC Adv. 2015;5(91):74347-74352. doi:10.1039/C5RA12404B

104. Yuan Z, Liu P, Hao YS, Ding Y, Cai KY. Construction of Agincorporated coating on Ti substrates for inhibited bacterial growth and enhanced osteoblast response. Colloid Surf B. 2018;171:597605. doi:10.1016/j.colsurfb.2018.07.064

105. Xu JW, Xu N, Zhou T, et al. Polydopamine coatings embedded with silver nanoparticles on nanostructured titania for long-lasting antibacterial effect. Surf Coat Tech. 2017;320:608-613. doi:10. 1016/j.surfcoat.2016.10.065

106. Wang HF, Wei LY, Wang ZQ, Chen SG. Preparation, characterization and long-term antibacterial activity of Ag-poly(dopamine)TiO2 nanotube composites. RSC $A d v$. 2016;6(17):14097-14104. doi:10.1039/C5RA22061K

107. Jia ZJ, Xiu P, Li M, et al. Bioinspired anchoring AgNPs onto micro-nanoporous $\mathrm{TiO} 2$ orthopedic coatings: trap-killing of bacteria, surface-regulated osteoblast functions and host responses. Biomaterials. 2016;75:203-222. doi:10.1016/j.biomaterials.2015. 10.035

108. Liu Q, Li M, Jia ZJ, et al. Effect of dopamine on the $\mathrm{TiO} 2$ nanotubes loaded with Ag nanoparticles. Rare Metal Mat Eng. 2014;43:276-280.

109. Yang Y, Zhang YM, Hu R, et al. Antibacterial and cytocompatible AgNPs constructed with the assistance of Mefp-1 for orthopaedic implants. RSC Adv. 2017;7(61):38434-38443. doi:10.1039/C7RA 06449G

110. Uhm SH, Lee SB, Song DH, Kwon JS, Han JG, Kim KN. Fabrication of bioactive, antibacterial $\mathrm{TiO} 2$ nanotube surfaces, coated with magnetron sputtered Ag nanostructures for dental applications. J Nanosci Nanotechnol. 2014;14(10):7847-7854. doi:10.1166/jnn.2014.9412

111. Uhm SH, Kwon JS, Song DH, et al. Long-term antibacterial performance and bioactivity of plasma-engineered Ag-NPs/TiO2 nanotubes for bio-implants. J Biomed Nanotechnol. 2016;12 (10):1890-1906.

112. Zhang LC, Zhang LH, Yang Y, et al. Inhibitory effect of superhydrophobicity on silver release and antibacterial properties of super-hydrophobic Ag/TiO2 nanotubes. J Biomed Mater Res B. 2016;104(5):1004-1012. doi:10.1002/jbm.b.33454

113. Roguska A, Pisarek M, Belcarz A, et al. Improvement of the biofunctional properties of $\mathrm{TiO} 2$ nanotubes. Appl Surf Sci. 2016;388:775-785. doi:10.1016/j.apsusc.2016.03.128

114. Chernozem RV, Surmeneva MA, Krause B, et al. Functionalization of titania nanotubes with electrophoretically deposited silver and calcium phosphate nanoparticles: structure, composition and antibacterial assay. Mat Sci Eng C-Mater. 2019;97:420-430. doi:10.1016/j.msec.2018.12.045

115. Mei SL, Wang HY, Wang W, et al. Antibacterial effects and biocompatibility of titanium surfaces with graded silver incorporation in titania nanotubes. Biomaterials. 2014;35(14):4255-4265. doi:10.1016/j.biomaterials.2014.02.005

116. Ercan B, Taylor E, Alpaslan E, Webster TJ. Diameter of titanium nanotubes influences anti-bacterial efficacy. Nanotechnology. 2011;22(29):295102. doi:10.1088/0957-4484/22/29/295102 
117. Liu HL, Hou XG, Sun TT, et al. Cytocompatibility and antibacterial property of $\mathrm{N}+$ ions implanted $\mathrm{TiO} 2$ nanotubes. Surf Coat Tech. 2019;359:468-475. doi:10.1016/j.surfcoat.2018.12.108

118. Wang GM, Feng HQ, Hu LS, et al. An antibacterial platform based on capacitive carbon-doped $\mathrm{TiO} 2$ nanotubes after direct or alternating current charging. Nat Commun. 2018;9. doi:10.1038/ S41467-018-04317-2

119. Qian W, Yan C, He DF, et al. pH-triggered charge-reversible of glycol chitosan conjugated carboxyl graphene for enhancing photothermal ablation of focal infection. Acta Biomater. 2018;69:256264. doi:10.1016/j.actbio.2018.01.022

120. Zhuk I, Jariwala F, Attygalle AB, Wu Y, Libera MR, Sukhishvili SA. Self-defensive layer-by-layer films with bacteria-triggered antibiotic release. ACS Nano. 2014;8(8):7733-7745. doi:10.1021/ $\mathrm{nn} 500674 \mathrm{~g}$

121. Ma LW, Liu MZ, Liu HL, Chen J, Cui DP. In vitro cytotoxicity and drug release properties of $\mathrm{pH}$ - and temperature-sensitive core-shell hydrogel microspheres. Int $J$ Pharm. 2010;385(1-2):86-91. doi:10.1016/j.ijpharm.2009.10.037

122. Tao B, Deng Y, Song L, et al. BMP2-loaded titania nanotubes coating with $\mathrm{pH}$-responsive multilayers for bacterial infections inhibition and osteogenic activity improvement. Colloids Surf B Biointerfaces. 2019;177:242-252. doi:10.1016/j.colsurfb.2019.02. 014

123. Dong YW, Ye H, Liu Y, et al. pH dependent silver nanoparticles releasing titanium implant: a novel therapeutic approach to control peri-implant infection. Colloid Surf B. 2017;158:127-136. doi:10.1016/j.colsurfb.2017.06.034

124. Zhang T, Xie CL, Liu Y, Zhang FF, Xiao XF. pH-responsive drug release system of $\mathrm{Cu} 2+$-modified ammoniated $\mathrm{TiO} 2$ nanotube arrays. Mater Lett. 2018;215:95-98. doi:10.1016/j.matlet.2017.12. 080
125. Xiang YM, Liu XM, Mao CY, et al. Infection-prevention on Ti implants by controlled drug release from folic acid/ZnO quantum dots sealed titania nanotubes. Mat Sci Eng C-Mater. 2018;85:214224. doi:10.1016/j.msec.2017.12.034

126. Wang TT, Liu XM, Zhu YZ, et al. Metal Ion coordination polymercapped $\mathrm{pH}$-triggered drug release system on titania nanotubes for enhancing self-antibacterial capability of Ti implants. Acs Biomater Sci Eng. 2017;3(5):816-825. doi:10.1021/acsbiomaterials.7b00103

127. Cai KY, Jiang F, Luo Z, Chen XY. Temperature-responsive controlled drug delivery system based on titanium nanotubes. Adv Eng Mater. 2010;12(9):B565-B570. doi:10.1002/adem.201080015

128. Shen XK, Zhang F, Li K, et al. Cecropin B loaded TiO2 nanotubes coated with hyaluronidase sensitive multilayers for reducing bacterial adhesion. Mater Design. 2016;92:1007-1017. doi:10.1016/j. matdes.2015.12.126

129. Wu YH, Long YB, Li QL, et al. Layer-by-Layer (LBL) selfassembled biohybrid nanomaterials for efficient antibacterial applications. Acs Appl Mater Inter. 2015;7(31):17255-17263. doi:10. 1021/acsami.5b04216

130. Haas S, Hain N, Raoufi M, et al. Enzyme degradable polymersomes from hyaluronic acid-block-poly(epsilon-caprolactone) copolymers for the detection of enzymes of pathogenic bacteria. Biomacromolecules. 2015;16(3):832-841. doi:10.1021/bm501729h

131. Yuan Z, Huang SZ, Lan SX, et al. Surface engineering of titanium implants with enzyme-triggered antibacterial properties and enhanced osseointegration in vivo. J Mater Chem B. 2018;6 (48):8090-8104. doi:10.1039/C8TB01918E

132. Bariana M, Aw MS, Moore E, Voelcker NH, Losic D. Radiofrequency-triggered release for on-demand delivery of therapeutics from titania nanotube drug-eluting implants. Nanomedicine-Uk. 2014;9(8):1263-1275. doi:10.2217/nnm.13.93
International Journal of Nanomedicine

\section{Publish your work in this journal}

The International Journal of Nanomedicine is an international, peerreviewed journal focusing on the application of nanotechnology in diagnostics, therapeutics, and drug delivery systems throughout the biomedical field. This journal is indexed on PubMed Central, MedLine, CAS, SciSearch ${ }^{\mathbb{B}}$, Current Contents ${ }^{\mathbb{B}} /$ Clinical Medicine, $^{2}$
Journal Citation Reports/Science Edition, EMBase, Scopus and the Elsevier Bibliographic databases. The manuscript management system is completely online and includes a very quick and fair peer-review system, which is all easy to use. Visit http://www.dovepress.com/ testimonials.php to read real quotes from published authors. 